Check for updates

Cite this: Mater. Adv., 2020, 1,3267

Received 24th June 2020, Accepted 28th October 2020

DOI: 10.1039/d0ma00449a

rsc.li/materials-advances

\section{Porous carbons from sustainable sources and mild activation for targeted high-performance $\mathrm{CO}_{2}$ capture and storage $\dagger$}

\begin{abstract}
Abdulsalam M. Aljumialy (D) ab and Robert Mokaya (D) *a
Carbon activation typically involves corrosive activating reagents such as $\mathrm{KOH}$ and $\mathrm{NaOH}$. In this report, a less corrosive activating agent, i.e., potassium oxalate (PO), was explored for the preparation of activated carbons from biomass (hydrochar from sawdust, SD), polypyrrole (Ppy), or pre-mixed (SD + PPy) precursors. The resulting activated carbons have surface area of up to $2740 \mathrm{~m}^{2} \mathrm{~g}^{-1}$ and pore volume up to $1.7 \mathrm{~cm}^{3} \mathrm{~g}^{-1}$, and depending on activation conditions and/or type of precursor, are either highly microporous (up to $91 \%$ surface area from micropores) or highly mesoporous (up to $96 \%$ of surface area from mesopores). Unlike hydroxide activation, varying the PO/precursor ratio, within the range of $2-6$, does not have a significant effect on porosity; carbons activated at $\mathrm{PO} /$ precursor ratio of 2, 4, 5 or 6 have comparable surface area. In contrast, activation temperature plays a critical role in determining the textural properties at any $\mathrm{PO} /$ precursor ratio. In this regard, a low PO/precursor ratio of 2 can achieve the full range of porosity, which not only offers a more eco-friendly and sustainable activation process but also allows easier control of the porosity by simple choice of activation temperature or type of precursor. The porosity of the activated carbons may be tailored towards 6 to $8 \AA$ pore channels, which are excellent for $\mathrm{CO}_{2}$ storage at low pressure (i.e., post-combustion $\mathrm{CO}_{2}$ capture) where at $25^{\circ} \mathrm{C}$, the carbons capture up to 1.4 and $4.4 \mathrm{mmol} \mathrm{g}^{-1}$ of $\mathrm{CO}_{2}$ at 0.15 bar and 1 bar, respectively. The porosity can also be tailored towards mesoporosity, which is suited for moderate to high pressure (pre-combustion) $\mathrm{CO}_{2}$ storage, which reaches $20.3 \mathrm{mmol} \mathrm{g}$ at 20 bar and $30.1 \mathrm{mmol} \mathrm{g}^{-1}$ at 40 bar at $25{ }^{\circ} \mathrm{C}$. For high surface area samples, the porosity is favourable for pre-combustion $\mathrm{CO}_{2}$ capture, via pressure swing adsorption processes at an adsorption pressure of up to 40 bar and desorption at 1 bar, from gas mixtures (e.g., $60: 40 \mathrm{H}_{2} / \mathrm{CO}_{2}$ ) where the carbons achieve excellent working capacity.
\end{abstract}

\section{Introduction}

Carbonaceous materials such as activated carbon have been widely used in a range of applications including as electrodes in supercapacitors and in gas $\left(\mathrm{CO}_{2}\right.$ and $\left.\mathrm{H}_{2}\right)$ storage. ${ }^{1-10}$ Activated carbons are attractive due to their ease of preparation, high thermal and mechanical stability and variable packing density. ${ }^{11-21}$ The performance of activated carbons in most of their current and potential applications is dependent on their textural properties. The ability to control the textural properties of activated carbon is therefore very important in efforts aimed at fully exploiting their potential, especially in energy related gas storage applications where there is currently a great deal of

${ }^{a}$ School of Chemistry, University of Nottingham, University Park, Nottingham NG7 2RD, UK. E-mail: r.mokaya@nottingham.ac.uk

${ }^{b}$ Department of Chemistry, College of Science, University of Anbar, Anbar, Iraq

$\dagger$ Electronic supplementary information (ESI) available: One table and seventeen (17) additional figures; TGA curves, XRD patterns, and $\mathrm{CO}_{2}$ uptake isotherms. See DOI: $10.1039 /$ d0ma00449a attention on the storage and transportation of hydrogen and $\mathrm{CO}_{2}$. The use of hydrogen for energy production can mitigate $\mathrm{CO}_{2}$ emissions by reducing reliance on fossil fuels. ${ }^{22,23}$ The on-going use of fossil fuels generates $\mathrm{CO}_{2}$, which is considered to be a primary contributing factor to global warming. ${ }^{24,25}$ Therefore, it is necessary to mitigate $\mathrm{CO}_{2}$ emissions, especially from flue gases emanating from fossil fuel power stations prior to their release into the atmosphere. ${ }^{22-25}$ One of the ideas being explored for the removal of $\mathrm{CO}_{2}$ involves adsorption of $\mathrm{CO}_{2}$ onto solid adsorbents, ${ }^{26-34}$ as an alternative to amines based industrial processes. The amine based processes suffer from corrosion issues and have high regeneration costs as $\mathrm{CO}_{2}$ binds strongly to amines. In general, the amount of gas (hydrogen or $\mathrm{CO}_{2}$ ) adsorbed and stored on a solid depends on the porosity of the absorbent. For this reason, there have been increasing efforts to prepare tailorable porous materials with optimised porosity and gas uptake. ${ }^{26-37}$

The synthesis of activated carbon often requires several steps based on either physical or chemical activation. The former 
involves physical treatment of a carbonaceous precursor at high temperature (typically above $900{ }^{\circ} \mathrm{C}$ ) under oxidising gas conditions (flow of steam or $\mathrm{CO}_{2}$ ) while in the later, the carbonaceous precursor is acted on by a chemical agent at medium to high temperature (typically up to $900{ }^{\circ} \mathrm{C}$ ). Chemical activation involves the use of a reagent (such as $\mathrm{H}_{3} \mathrm{PO}_{3}, \mathrm{ZnCl}_{2}$ or $\mathrm{KOH}$ ) as an activating agent, and is widely used because it can generate activated carbon with higher surface area and/or narrow pore size distribution. The advantages of chemical activation, i.e., lower temperature and shorter operation time, and which can offer high carbon yields and better control of porosity, have triggered interest that has so far explored a wide range of carbon precursors including polymers, ${ }^{38-40}$ lignin, ${ }^{16}$ carbon nanotubes, ${ }^{34}$ olive stones, ${ }^{41,42}$ rice husks, ${ }^{43}$ and other sources. ${ }^{36,37}$

One of most extensively explored activating agents for the synthesis of activated carbons is potassium hydroxide via the so-called hydroxide activation. The use of $\mathrm{KOH}$, however, suffers from drawbacks related to a toxic and corrosive nature. Thus milder activating agents but which offer similar or better textural properties are highly desired. There is growing research interest in the use of less corrosive and less toxic activating agents or porogens that go beyond hydroxide activation. ${ }^{4-53}$ For example, Sevilla and co-workers reported on the use of a mixture of melamine and potassium oxalate (PO) as activating agents for the preparation of biomass derived carbons suitable for use as electrode materials for supercapacitors. ${ }^{46}$ We have shown that the presence of melamine, in addition to PO, is necessary for achieving high surface area $\left(>1600 \mathrm{~m}^{2} \mathrm{~g}^{-1}\right)$ carbons that are potentially useful for pre-combustion $\mathrm{CO}_{2}$ capture. ${ }^{47}$ The added melamine was thought to have the function of an activator, which is not unexpected as PO is a milder activating agent compared to $\mathrm{KOH} \cdot{ }^{46,47}$ Indeed, most studies that have used PO as activating agent report carbons with low to medium surface area (typically $<1500 \mathrm{~m}^{2} \mathrm{~g}^{-1}$ ) for activation at $800{ }^{\circ} \mathrm{C}$ or below. ${ }^{44-51}$ The low to moderate surface is observed even when additives such as $\mathrm{CaCO}_{3},{ }^{49,50}$ or $\mathrm{CaSO}_{4},{ }^{51}$ are included as porogens or activation enhancers. One previous study $^{52}$ reported higher surface area (up to $2500 \mathrm{~m}^{2} \mathrm{~g}^{-1}$ ) but other studies show surface area below $1500 \mathrm{~m}^{2} \mathrm{~g}^{-1}$ under similar activation conditions. ${ }^{47}$ The surface area for PO activated carbons may be increased if higher activation temperature $\left(>800{ }^{\circ} \mathrm{C}\right)$ is used, ${ }^{47,53}$ but such a high temperature is undesirable from a sustainability point of view.

It is known that the amount of activating agent and the activation temperature play a role in determining the porosity generated in $\mathrm{KOH}$ activated carbons. Recently, we have shown that the $\mathrm{O} / \mathrm{C}$ ratio of any carbonaceous solid used as starting material (i.e., precursor) is a key consideration in determining porosity of $\mathrm{KOH}$ activated carbons, with high $\mathrm{O} / \mathrm{C}$ ratio favouring greater surface area and pore volume. ${ }^{54,55}$ Given the attraction of PO as a mild activating agent, there is a need for a systematic study to clarify on how activation with PO works under conditions that go beyond just varying the amount of $\mathrm{PO}$ and activation temperature to include a variety of precursors with a range of $\mathrm{O} / \mathrm{C}$ ratios. Such a systematic study is needed as, so far, no clear trends are evident from previous studies, with some reporting very low surface area, while others report either an increase or a decrease in surface area for higher amounts of PO. ${ }^{4-53}$ This report, explores the preparation of PO activated carbons from biomass and pre-mixed precursors that contain a mix of carbonaceous materials that are known to respond differently to similar levels of activation. The full range of possible porosity development using $\mathrm{PO}$ as activator is investigated, and the resulting materials are explored as $\mathrm{CO}_{2}$ storage materials both for low pressure (postcombustion) and medium to high pressure (pre-combustion) conditions.

\section{Experimental section}

\subsection{Material synthesis}

The sawdust was converted to hydrochar via hydrothermal carbonisation as follows; $6.4 \mathrm{~g}$ of sawdust was dispersed in $20 \mathrm{ml}$ deionized water, placed in a stainless-steel autoclave and heated at $250{ }^{\circ} \mathrm{C}$ for $2 \mathrm{~h}$, and then cooled to room temperature. The resulting carbonaceous solid was recovered by filtration, washed with deionized water and dried in an oven at $120{ }^{\circ} \mathrm{C}$ to yield the sawdust derived hydrochar (designated as SD). Polypyrrole (Ppy) was synthesised by mixing $3 \mathrm{~g}$ of pyrrole with 200 $\mathrm{ml}$ of $0.5 \mathrm{M} \mathrm{FeCl}_{3}$ solution and stirring the mixture for $2 \mathrm{~h}$ at room temperature. The polypyrrole, at a yield close to $100 \%$, was then recovered, washed with distilled water and dried in an oven at $120{ }^{\circ} \mathrm{C}$.

For activation, the required amount of potassium oxalate (PO) was added to the carbon precursor (sawdust derived hydrochar, SD or Ppy or a mixture of SD + Ppy) and thoroughly mixed at $\mathrm{PO} /$ precursor mass ratio of $2,4,5$ or 6 . For activation of pre-mixed precursors containing SD and Ppy, three sets of samples were prepared from mixtures of SD : Ppy at weight ratio of $2: 1,1: 1$, or $1: 2$. The resulting mixture of $P O$ and the chosen precursor was placed in an alumina boat and inserted into a tubular furnace and heated at a ramp rate of $5{ }^{\circ} \mathrm{C} \mathrm{min}^{-1}$ to 600 , 700,800 or $900{ }^{\circ} \mathrm{C}$ under a flow of nitrogen. It was held for $1 \mathrm{~h}$ at the target temperature and then cooled to room temperature under a flow of nitrogen. The resulting samples were recovered and washed several times by stirring in $10 \%$ hydrochloric acid at room temperature followed by filtration and washing with deionized water until the filtrate was free of $\mathrm{Cl}^{-}$ions according to the $\mathrm{AGNO}_{3}$ test, and then dried in an oven at $120{ }^{\circ} \mathrm{C}$. SD derived samples were designated as $\mathrm{SD} x T$, where $x$ is $\mathrm{PO} / \mathrm{SD}$ ratio, and $T$ is activation temperature. Ppy derived samples were designated as PpyxT, where $x$ is PO/Ppy ratio and $T$ is activation temperature. Samples derived from pre-mixed precursors of SD and Ppy were designated as $\operatorname{Ppy}-\mathrm{SD}(a-b) x T$, where $a-b$ is the Ppy-SD ratio, $x$ is $\mathrm{PO} /$ precursor ratio, and $T$ is activation temperature such that a carbon prepared at $800{ }^{\circ} \mathrm{C}$ and $\mathrm{PO} /$ precursor ratio of 2 from a pre-mixed precursor containing a 1:2 Ppy: SD ratio is designated as Ppy-SD(1-2)2800.

\subsection{Characterization methods}

Thermogravimetric analysis (TGA) was performed using a TA Instruments SDT Q600 analyzer at heating rate of $10{ }^{\circ} \mathrm{C} / \mathrm{min}$ 
under flowing air conditions. Powder XRD patterns were obtained using a PANalytical X'Pert PRO diffractometer with $\mathrm{CuK}_{\alpha}$ radiation $(\lambda=1.5406 \AA)(40 \mathrm{kV}, 40 \mathrm{~mA}), 0.02$ step size and $2 \mathrm{~s}$ step time for values of $2 \theta$ between $2^{\circ}$ and $80^{\circ}$. Elemental analysis (CHNO) was performed using an Exeter Analytical CE-440 Elemental Analyser. Nitrogen sorption isotherms and textural properties were determined at $-196{ }^{\circ} \mathrm{C}$ using nitrogen sorption in a conventional volumetric technique on a Micrometrics 3Flex sorptometer. Before analysis, the samples were outgassed under vacuum at $230{ }^{\circ} \mathrm{C}$ for $16 \mathrm{~h}$. Surface areas of the carbons were determined using the BET method based on adsorption data in the relative pressure range $\left(P / P_{0}\right)$ range of 0.01-0.2. The relative pressure range was selected to ensure a positive $y$-axis intercept from multipoint BET fitting (such that $C>0)$ and that $V_{\text {ads }}\left(1-P / P_{0}\right)$ would increase with $P / P_{0}{ }^{56}$ The total pore volume was calculated from the amount of nitrogen adsorbed at relative pressure $\left(P / P_{0}\right)$ of $c a$. 0.99 . The micropore surface area and micropore pore volume were determined using $t$-plot analysis. The pore size distributions were obtained via Nonlocal density functional theory (NLDFT) methods using nitrogen adsorption data. Scanning electron microscopy (SEM) analysis was performed using a JEOL 7100F microscope. The carbon samples were loaded on a carbon conductive sticky tape prior to analysis.

\section{$2.3 \mathrm{CO}_{2}$ uptake measurements}

$\mathrm{CO}_{2}$ uptake was determined using a Hiden Isochema XEMIS instrument at $25{ }^{\circ} \mathrm{C}$ and pressure of up to $40 \mathrm{bar}$. The carbons were outgassed for $3 \mathrm{~h}$ under vacuum at $240{ }^{\circ} \mathrm{C}$ prior to performing the $\mathrm{CO}_{2}$ uptake measurements. Our measurements directly determined the excess $\mathrm{CO}_{2}$ uptake. For low pressure measurements (up to 1 bar), we report the excess uptake as it is very close to the total uptake. At 20 bar and above, we report both the excess and total uptake, wherein the latter is obtained by factoring in the density of the $\mathrm{CO}_{2}$ under the measurement conditions and the total pore volume of the sample according to the following equation; $\theta_{\mathrm{T}}=\theta_{\mathrm{Exc}}+d_{\mathrm{CO} 2} \times V_{\mathrm{T}}$, where; $\theta_{\mathrm{T}}$ is total $\mathrm{CO}_{2}$ uptake, $\theta_{\mathrm{Exc}}$ is excess $\mathrm{CO}_{2}$ uptake, $d_{\mathrm{CO} 2}$ is density $\left(\mathrm{g} \mathrm{cm}^{-3}\right)$ of $\mathrm{CO}_{2}$ gas at $25{ }^{\circ} \mathrm{C}$ and relevant pressure, and $V_{\mathrm{T}}$ is pore volume $\left(\mathrm{cm}^{3} \mathrm{~g}^{-1}\right)$ of the carbon. The $\mathrm{CO}_{2}$ density is available from the National Institute of Standards and Technology (NIST) website (http://www.nist.gov/).

\section{Results and discussion}

\subsection{Carbons derived from sawdust hydrochar}

3.1.1 Nature and elemental composition. The carbon yields of samples activated at PO/SD ratio of 2, 4, 5 or 6 at $600,700,800$ or $900{ }^{\circ} \mathrm{C}$ are summarised in Table 1 . The yields vary from 18 to $21 \%$, for samples activated at the highest temperature $\left(900{ }^{\circ} \mathrm{C}\right.$ ), and 43 to $46 \%$ for samples activated at the lowest temperature $\left(600^{\circ} \mathrm{C}\right)$. It is noteworthy that activation at $\mathrm{PO} / \mathrm{SD}$ ratio of between 2 and 6 at any given temperature, does not appear to have any significant effect on the carbon yield. In general, it is only the activation temperature that
Table 1 Yield and elemental analysis of carbons activated at 600, 700, 800 or $900{ }^{\circ} \mathrm{C}$, and $\mathrm{PO} / \mathrm{SD}$ ratio of $2,4,5$ or 6

\begin{tabular}{llllll}
\hline & & \multicolumn{5}{l}{\begin{tabular}{l} 
Elemental composition (wt\%) \\
Yield \\
\cline { 3 - 6 } Sample
\end{tabular}} & $\mathrm{C}$ & $\mathrm{H}$ & $\mathrm{N}$ & $\mathrm{O}$ \\
\hline Sawdust & & 48.5 & 5.7 & 0.3 & 45.5 \\
Hydrochar & & 57.5 & 5.2 & 0.4 & 36.9 \\
SD2600 & 43 & 78.9 & 1.4 & 0.7 & 19.0 \\
SD2700 & 41 & 81.1 & 0.2 & 0.2 & 18.5 \\
SD2800 & 33 & 87.7 & 0.0 & 0.1 & 12.2 \\
SD2900 & 21 & 90.7 & 0.0 & 0.2 & 9.1 \\
SD4600 & 46 & 77.4 & 0.9 & 0.5 & 21.2 \\
SD4700 & 41 & 83.7 & 0.3 & 0.3 & 15.7 \\
SD4800 & 36 & 82.7 & 0.3 & 0.1 & 16.9 \\
SD4900 & 18 & 87.3 & 0.0 & 0.0 & 12.7 \\
SD5800 & 37 & 83.9 & 0.3 & 0.1 & 15.7 \\
SD6800 & 37 & 88.9 & 0.0 & 0.0 & 11.1 \\
& & & & &
\end{tabular}

determines the carbon yield. Higher carbon yields are obtained at lower activation temperature to the extent that samples prepared at $600{ }^{\circ} \mathrm{C}$ have twice the yield of samples activated at $900{ }^{\circ} \mathrm{C}$. The yields obtained via PO activation are either similar (at $600{ }^{\circ} \mathrm{C}$ ) or much higher (at $\geq 700{ }^{\circ} \mathrm{C}$ ) that what has previously been reported for $\mathrm{KOH}$ activation. ${ }^{8,15,36-40}$ This illustrates a clear advantage of greater yields for PO activation compared to hydroxide activation. The elemental composition of the activated carbons is shown in Table 1 . The elemental $\mathrm{C}$ content increases from $49 \mathrm{wt} \%$ for the raw sawdust to $58 \mathrm{wt} \%$ in the hydrochar. The $\mathrm{C}$ content of the activated carbons varies between 77 and $91 \mathrm{wt} \%$. The largest C content (91 wt\%) is observed for carbons activated at the highest temperature $\left(900{ }^{\circ} \mathrm{C}\right)$ compared to $\mathrm{ca} .78 \mathrm{wt} \%$ for activation at $600{ }^{\circ} \mathrm{C}$. The $\mathrm{C} / \mathrm{H}$ atomic ratio in the activated carbons shows a significant increase at higher activation temperature due to greater amounts of $\mathrm{C}$, along with a drastic decrease in the $\mathrm{H}$ content. The $\mathrm{N}$ content is generally low, which is as expected for sawdust derived carbons, and is close to nil for samples activated at high temperature.

The thermal stability of the SD-derived activated carbons was investigated by thermogravimetric analysis (TGA) as shown in Fig. 1. The TGA curves show a first mass loss below $120{ }^{\circ} \mathrm{C}$ due to removal of water, followed by a significant mass loss at between 550 and $600{ }^{\circ} \mathrm{C}$ due to combustion of the carbon. The residual mass is lower than $4 \mathrm{wt} \%$, and typically $<1 \mathrm{wt} \%$, which indicates that the activated carbons were generally free of inorganic residues, with the exception of sample SD4900 that had residual mass of $c a$. 7\%. Carbons activated at higher temperature show higher resistance to combustion, with sample SD2900 and SD4900 having the highest thermal stability. The effect of activation temperature on thermal stability is exemplified by the fact that sample SD2600 had maximum burn-off at $500{ }^{\circ} \mathrm{C}$ compared to $600{ }^{\circ} \mathrm{C}$ for sample SD2900. Samples activated at PO/SD ratio of 4 (Fig. 1B) show slightly higher thermal stability than analogous samples activated at $\mathrm{PO} / \mathrm{SD}$ ratio of 2 (Fig. 1A). In order to assess the effect of the $\mathrm{PO} / \mathrm{SD}$ ratio on the thermal stability of the activated carbons, the stability of carbons activated at $800{ }^{\circ} \mathrm{C}$ and $\mathrm{PO} / \mathrm{SD}$ ratio of $2,4,5$ or 6 was investigated. The TGA curves (Fig. S1, ESI $\dagger$ ) indicate that 

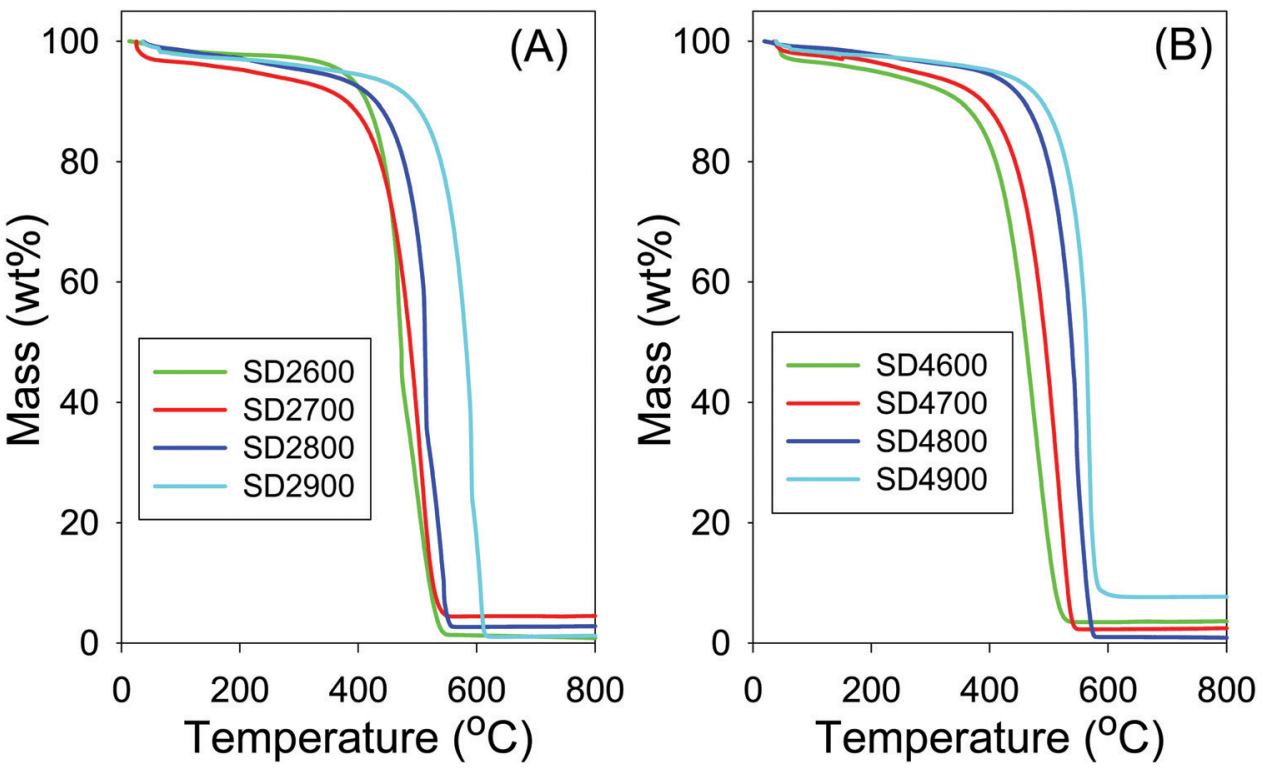

Fig. 1 Thermogravimetric analysis curves of carbons activated at PO/SD ratio of (A) 2 or (B) 4.

thermal stability slightly rises when the $\mathrm{PO} / \mathrm{SD}$ ratio increases, such that the carbon activated at highest $\mathrm{PO} / \mathrm{SD}$ ratio of 6 is the most resistant to combustion.

The powder XRD patterns of the activated carbons (Fig. S2, ESI $\dagger$ ) show very broad peaks at $2 \theta=26^{\circ}$ and $43^{\circ}$, which relate to the graphitic/turbostratic nature of the carbons. ${ }^{56}$ The XRD patterns indicate that the $\mathrm{PO} / \mathrm{SD}$ ratio does not significantly affect the nature of the carbons. The XRD patterns of some of the carbons show sharp peaks that may suggest the presence of inorganic residues from the activating agent, although the corresponding TGA curves (Fig. 1) show that such amounts are very low. Where present, the sharp peaks appear to arise from residual $\mathrm{KCl}$ from the washing process. The sharp but low intensity peak at $2 \theta=26.5^{\circ}$ may be ascribed to (200) diffraction of $\mathrm{KCl}$ but the absence of other expected diffractions suggest that the amount of the inorganic residue is very low, which is consistent with the TGA data in Fig. 1. In general, the XRD patterns of the carbon samples are consistent with their being amorphous but with some graphitic domains, which is typical of activated carbons. ${ }^{14-21}$ The XRD patterns and TGA curves are consistent with the expectation that higher activation temperature favours the presence of graphitic domains in the activated carbons and thus enhances thermal stability. In this respect, the trend in thermal stability of the PO activated carbons as a function of activation temperature is similar to what has previously been observed for $\mathrm{KOH}$ activated carbons. ${ }^{14-21}$ Scanning electron microscopy (SEM) was used to image and monitor changes in morphology of the sawdust biomass following hydrothermal carbonisation and activation. The SEM images of the sawdust, sawdust-derived hydrochar and representative activated carbons are shown in Fig. 2. The sawdust has a cellular-like structure that is typical of biomass, and following the hydrothermal carbonisation process, where the biomass is converted to hydrochar, some of the morphology of the sawdust appears to be retained. ${ }^{13,46}$ On the other hand, the activated carbons have morphology of sheet-like and irregularly shaped particles. ${ }^{14}$ It is interesting to note that the activated carbons have some particles with a morphology that is similar to that of the sawdust-derived hydrochar. This observation suggests that the potassium oxalate is a much milder activating agent compared to $\mathrm{KOH}$; the latter significantly disrupts the morphology and structure of the precursor starting material even when mild activation is performed. ${ }^{12-20}$

\subsubsection{Porosity}

Effect of activation temperature. The nitrogen sorption isotherms and the corresponding pore size distribution (PSD) curves of carbons activated at $\mathrm{PO} / \mathrm{SD}$ ratio of 2 at 600 to $900{ }^{\circ} \mathrm{C}$ are shown in Fig. 3. All the activated carbons, except SD2900, show type I isotherms that are typical of microporous materials. High nitrogen sorption occurs at low relative pressure $\left(P / P_{0}<0.1\right)$ due to micropore filling, ${ }^{57}$ and no significant adsorption occurs at $P / P_{0}$ greater than 0.1 except for sample SD2900. For activation at $800{ }^{\circ} \mathrm{C}$, there is a slight broadening of the adsorption 'knee' in the isotherm, which suggests limited widening in the pore size distribution. The 'knee' broadening is particularly evident for sample SD2900, which shows an almost linear increase in adsorption up to $P / P_{0}$ of 0.4 suggesting the presence of larger micropores and a significant proportion of mesopores. ${ }^{58,59}$

As shown in Table 2, the surface area and pore volume of carbons prepared at $\mathrm{PO} / \mathrm{SD}$ ratio of 2 increases with activation temperature. The sample activated at $600{ }^{\circ} \mathrm{C}(\mathrm{SD} 2600)$ has surface area of $506 \mathrm{~m}^{2} \mathrm{~g}^{-1}$ and pore volume of $0.27 \mathrm{~cm}^{3} \mathrm{~g}^{-1}$, while the sample activated at $700{ }^{\circ} \mathrm{C}(\mathrm{SD} 2700)$ has surface area of $894 \mathrm{~m}^{2} \mathrm{~g}^{-1}$ and pore volume of $0.41 \mathrm{~cm}^{3} \mathrm{~g}^{-1}$. Sample SD2800 has surface area $\left(1463 \mathrm{~m}^{2} \mathrm{~g}^{-1}\right)$ and pore volume $\left(0.67 \mathrm{~cm}^{3} \mathrm{~g}^{-1}\right)$ that is $64 \%$ higher compared to that of sample SD2700. At the highest activation temperature of $900{ }^{\circ} \mathrm{C}$ (sample SD2900), the 

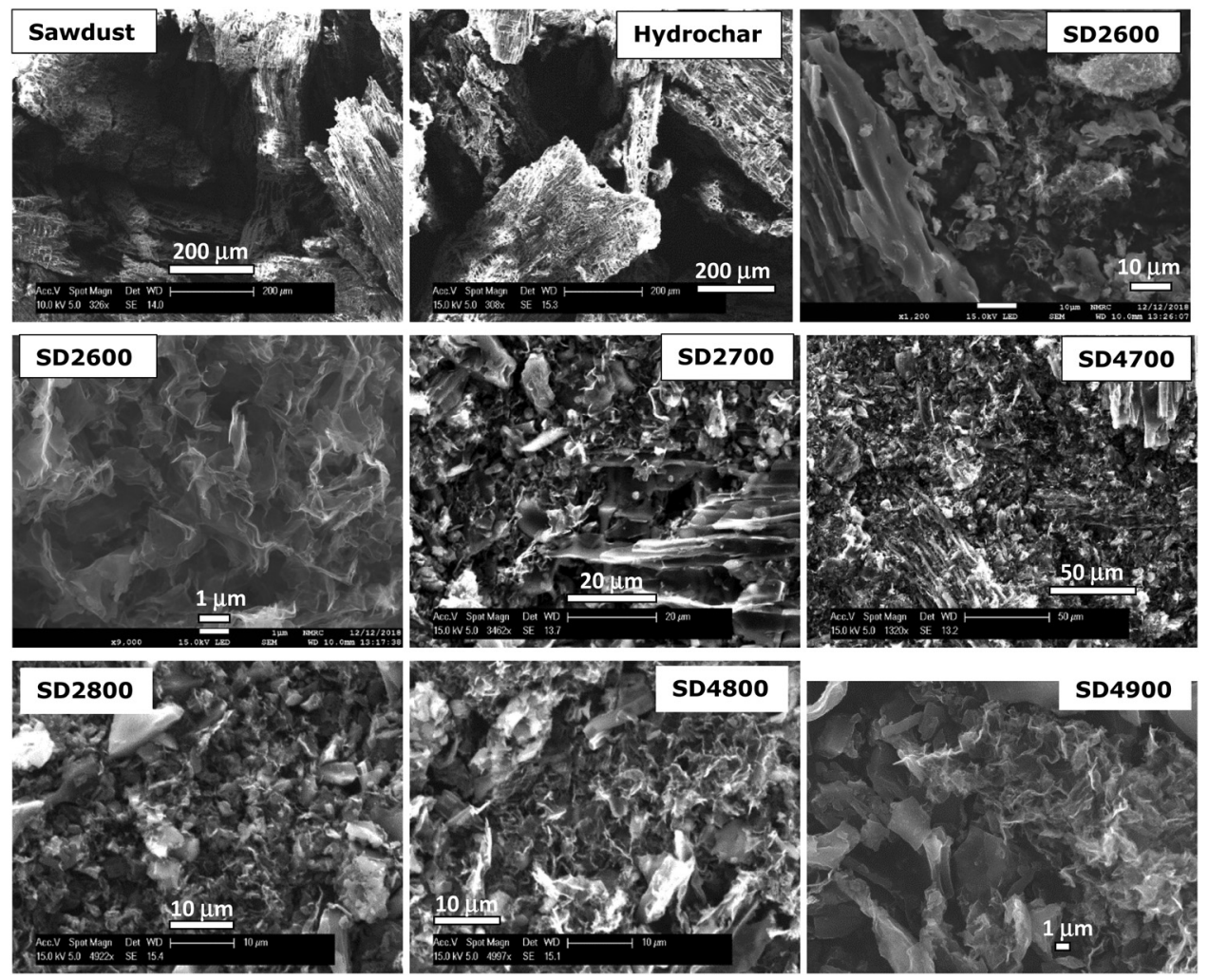

Fig. 2 SEM images of sawdust, sawdust-derived hydrochar and representative activated carbons.

surface area and pore volume increase further, respectively, by $60 \%$ (up to $2350 \mathrm{~m}^{2} \mathrm{~g}^{-1}$ ) and $89 \%$ (up to $1.27 \mathrm{~cm}^{3} \mathrm{~g}^{-1}$ ) compared to sample SD2800. There seems to be a step change in the surface area and pore volume between 800 and $900{ }^{\circ} \mathrm{C}$, which emphasises the role of activation temperature. In contrast, the micropore surface area decreases as the activation temperature rises from 800 to $900{ }^{\circ} \mathrm{C}$ (Table 2); the proportion of the micropore surface area is $34 \%$ for sample SD2900, compared to $90 \%$ for sample SD2800. According to the pore size distribution (PSD) curves shown in Fig. 3B, the pore size of carbons prepared at $\mathrm{PO} / \mathrm{SD}$ ratio of 2 , at $600{ }^{\circ} \mathrm{C}$ and $700{ }^{\circ} \mathrm{C}$, is almost exclusively dominated by 6 and $8 \AA$ pores (Table 2),
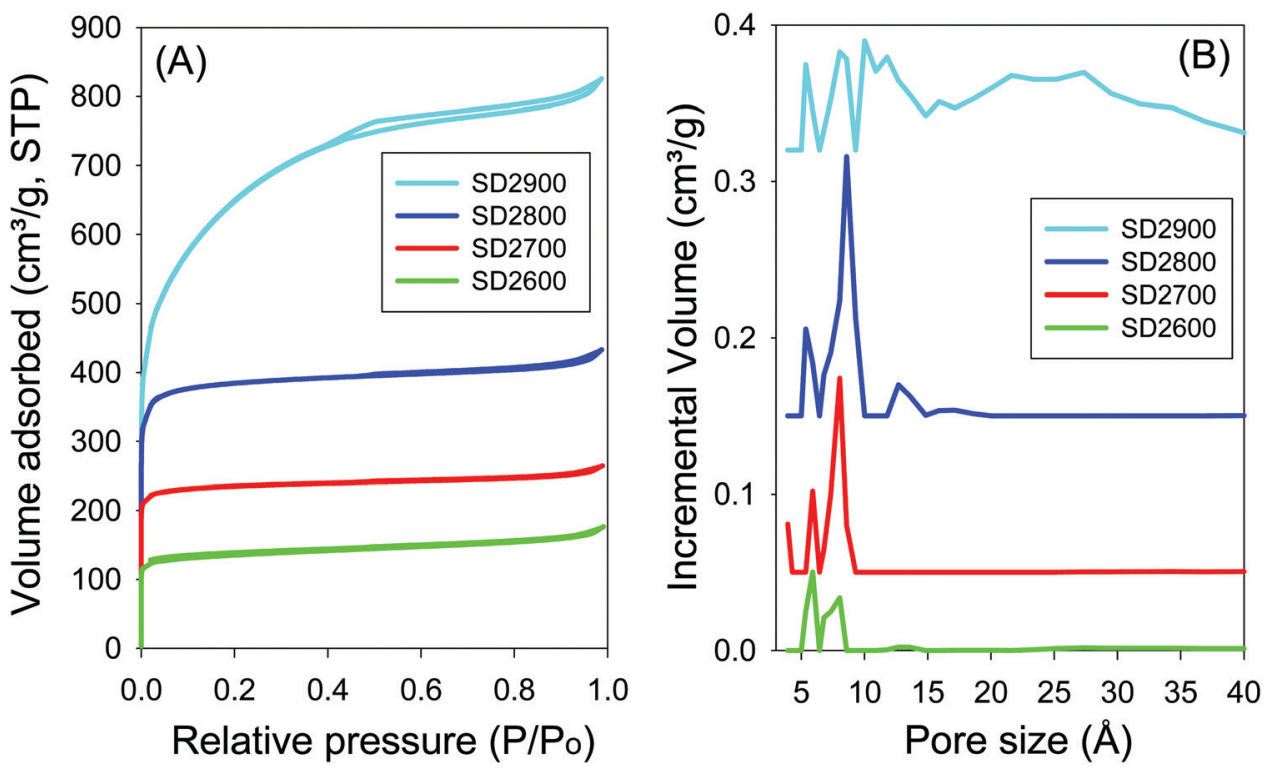

Fig. 3 Nitrogen sorption isotherms (A) and pore size distributions curves (B) for carbon samples activated at temperatures between 600 and $900{ }^{\circ} \mathrm{C}$ and $\mathrm{PO} / \mathrm{SD}$ ratio of 2 . 
Table 2 Textural properties and $\mathrm{CO}_{2}$ uptake of carbons derived from sawdust hydrochar

\begin{tabular}{|c|c|c|c|c|c|c|c|}
\hline \multirow[b]{2}{*}{ Sample } & \multirow{2}{*}{$\begin{array}{l}\text { Surface area }{ }^{a} \\
\left(\mathrm{~m}^{2} \mathrm{~g}^{-1}\right)\end{array}$} & \multirow[b]{2}{*}{$\% \mu \mathrm{SA}$} & \multirow{2}{*}{$\begin{array}{l}\text { Pore volume } \\
\left(\mathrm{cm}^{3} \mathrm{~g}^{-1}\right)\end{array}$} & \multirow{2}{*}{$\begin{array}{l}\text { Pore } \\
\text { size }(\AA)\end{array}$} & \multicolumn{3}{|c|}{$\mathrm{CO}_{2}$ uptake $\left(\mathrm{mmol} \mathrm{g}^{-1}\right)$ at $25{ }^{\circ} \mathrm{C}$} \\
\hline & & & & & 0.15 bar & $1 \mathrm{bar}$ & 20 bar $^{c}$ \\
\hline SD2600 & 506 (411) & 81 & $0.27(0.16)$ & $6 / 8$ & 1.2 & 2.6 & $4.6(4.8)$ \\
\hline SD2800 & $1463(1311)$ & 90 & $0.67(0.53)$ & $6 / 8 / 13$ & 1.2 & 4.3 & $11.9(12.5)$ \\
\hline SD2900 & $2350(800)$ & 34 & $1.27(0.32)$ & $6 / 8 / 12 / 27$ & 0.7 & 3.4 & $18.0(19.1)$ \\
\hline SD4600 & 575 (499) & 87 & $0.30(0.20)$ & $6 / 8$ & 1.2 & 2.9 & $5.1(5.4)$ \\
\hline SD4700 & $972(875)$ & 90 & $0.46(0.35)$ & $6 / 8$ & 1.2 & 3.7 & $7.6(8.0)$ \\
\hline SD5800 & 1498 (1321) & 88 & $0.70(0.50)$ & $6 / 9 / 13$ & 1.2 & 4.3 & $12.8(13.4)$ \\
\hline SD6800 & $1470(1294)$ & 88 & $0.71(0.52)$ & $6 / 8 / 13$ & 1.2 & 4.4 & $12.6(13.2)$ \\
\hline
\end{tabular}

${ }^{a}$ Values in parenthesis are micropore surface area. ${ }^{b}$ Values in parenthesis are micropore volume. ${ }^{c}$ Values in parenthesis are total $\mathrm{CO}_{2}$ uptake.

while sample SD2800 shows a noticeable proportion of $13 \AA$ pores. With rise in activation temperature to $900{ }^{\circ} \mathrm{C}$, sample SD2900 shows a further widening of the pore size with a significant proportion of $27 \AA$ pores (Fig. S3, ESI $\dagger$ ). The presence of larger pores for samples activated at higher temperatures may be attributed to a higher level of activation caused by greater gasification. ${ }^{60}$

For samples activated at $\mathrm{PO} / \mathrm{SD}$ ratio of 4 , the nitrogen sorption isotherms and the corresponding pore size distribution (PSD) curves are shown in Fig. 4, and the textural properties are summarised in Table 2. The isotherms of carbons activated at 600 to $800{ }^{\circ} \mathrm{C}$ are type I, typical of microporous materials, where high nitrogen sorption occurs at low relative pressure $\left(P / P_{0}<0.1\right)$ due to micropore filling. The isotherms of samples SD4600 and SD4700 exhibit a sharp adsorption knee, and plateau at relative pressure higher than 0.1, i.e., no noticeable adsorption of nitrogen occurs at relative pressure higher than 0.1. The isotherm of sample SD4800 shows a gentle adsorption knee, and at the highest activation temperature of
$900{ }^{\circ} \mathrm{C}$ (sample SD4900), the isotherm shows a broad adsorption knee with an almost linear increase in adsorption up to $P / P_{0}$ of 0.4 that suggests the presence of significant mesoporosity. ${ }^{58,59}$ Regarding textural properties, sample SD4600 has surface area of $575 \mathrm{~m}^{2} \mathrm{~g}^{-1}$ and pore volume of $0.3 \mathrm{~cm}^{3} \mathrm{~g}^{-1}$, which increase, respectively, to $972 \mathrm{~m}^{2} \mathrm{~g}^{-1}$ and $0.46 \mathrm{~cm}^{3} \mathrm{~g}^{-1}$ for sample SD2700. Sample SD4800 has surface area and pore volume of $1441 \mathrm{~m}^{2} \mathrm{~g}^{-1}$ and $0.0 .68 \mathrm{~cm}^{3} \mathrm{~g}^{-1}$, respectively, while at the highest activation temperature of $900{ }^{\circ} \mathrm{C}$ (sample SD4900), the surface area and pore volume are higher, respectively, by $53 \%$ (up to $2205 \mathrm{~m}^{2} \mathrm{~g}^{-1}$ ) and $95 \%$ (up to $1.33 \mathrm{~cm}^{3} \mathrm{~g}^{-1}$ ) compared to the sample activated at $800{ }^{\circ} \mathrm{C}$ (SD4800). On the other hand, the proportion of micropore surface area decreases from $87 \%$ for the sample SD2800 to $32 \%$ for SD2900. Fig. 4B shows the pore size distributions (PSDs) of SD4T carbons, and Table 2 summarises the pore size maxima values. The carbons activated at 600 and $700{ }^{\circ} \mathrm{C}$ are dominated by pores centred at $c a$. $6-8 \AA$, while sample SD4800 shows a small proportion of pores of size $14 \AA$ At. At the highest activation temperature of $900{ }^{\circ} \mathrm{C}$, the PSD of sample
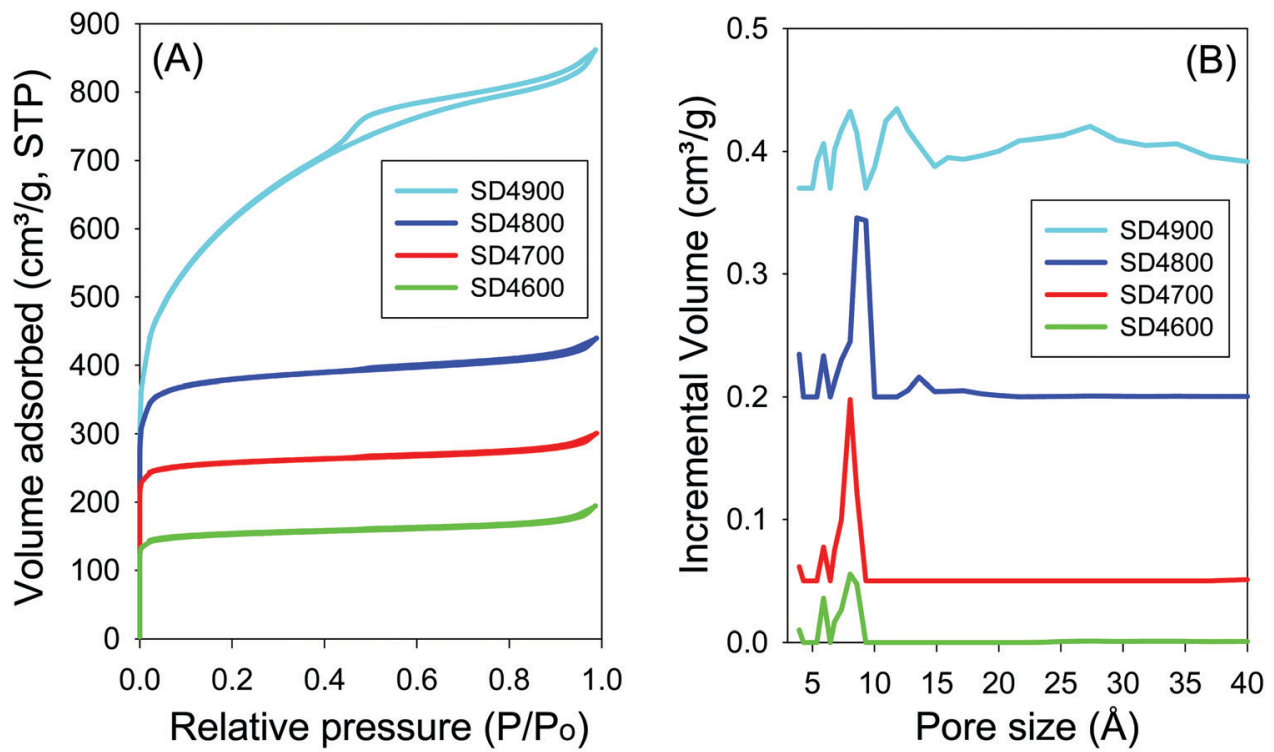

Fig. 4 Nitrogen sorption isotherms (A) and pore size distribution curves (B) for carbon samples activated at temperatures between 600 and $900{ }^{\circ} \mathrm{C}$ and $\mathrm{PO} / \mathrm{SD}$ ratio of 4 . 
SD4900 shows a significant proportion of pores of size $30 \AA$ and above (Fig. S3, ESI $\dagger$ ).

Effect of $P O / S D$ ratio. In order to more fully explore the effect of increasing the amount of activating agent, additional samples were activated at $\mathrm{PO} / \mathrm{SD}$ ratios of 5 or 6 at $800{ }^{\circ} \mathrm{C}$. Fig. 5 shows the nitrogen sorption isotherms and pore size distribution curves for samples activated at $800{ }^{\circ} \mathrm{C}$ and $\mathrm{PO} / \mathrm{SD}$ ratio of $2,4,5$ or 6 . The samples show similar isotherms (i.e., type I) that are typical of microporous materials, with almost all the nitrogen adsorbed in the low relative pressure domain $\left(P / P_{0}<0.1\right)$. Increasing the $\mathrm{PO} / \mathrm{SD}$ ratio has little effect on the shape of the isotherm and amount of nitrogen uptake. Additionally, increasing the $\mathrm{PO} / \mathrm{SD}$ ratio does not significantly affect the surface area, which remains $c a .1450 \mathrm{~m}^{2} \mathrm{~g}^{-1}$. It is remarkable that sample SD2800 (activated at a low $\mathrm{PO} / \mathrm{SD}$ ratio of 2) has surface area and pore volume $\left(1470 \mathrm{~m}^{2} \mathrm{~g}^{-1}\right.$ and $0.7 \mathrm{~cm}^{3} \mathrm{~g}^{-1}$, respectively), which is similar to that of sample SD6800 that was activated at much higher PO/SD ratio of 6 . The pore size distribution (PSD) curves of carbons activated at $\mathrm{PO} / \mathrm{SD}$ ratios of $2,4,5$ or 6 at $800{ }^{\circ} \mathrm{C}$ are shown in Fig. $5 \mathrm{~B}$, and the pore maxima are summarised in Table 2. Increasing the $\mathrm{PO} / \mathrm{SD}$ ratio from 2 to 4 or 5 does not affect the pore size distribution; samples SD2800, SD4800 and SD5800 all have three pore maxima at 6, 9 and $13 \AA$. However, the PSD curve of the sample activated with $\mathrm{PO} / \mathrm{SD}$ ratio of 6 shows four pore maxima at $c a$. 6, 8, 9 and $13 \AA$ A. In general, therefore, increasing the amount of activating agent does not significantly affect the PSD; there are no pores larger than $13 \AA$ for any of the samples (i.e. SD2800, SD4800, SD5800 and SD6800) activated at increasingly higher $\mathrm{PO} / \mathrm{SD}$ ratios. These findings show that using potassium oxalate as an activating agent offers (in addition to the advantage of being a less corrosive and less toxic activating agent compared to $\mathrm{KOH}$ ) control of porosity by simply modifying the activation temperature. The ability to strictly tailor pore size of activated carbons is one of the barriers to the wide use of carbons in energy-related applications. ${ }^{61}$ From what has been discussed above, and as shown in Table 2, varying the PO/SD ratios does not significantly affect the porosity of the obtained carbons. In contrast, the activation temperature plays a critical role in determining the textural properties of the activated carbons.

Regarding the mechanism of activation, ${ }^{46,52}$ as the mixture of SD and PO is heated in the range of 500 to $600{ }^{\circ} \mathrm{C}$, decomposition of PO occurs as follows; $\mathrm{K}_{2} \mathrm{C}_{2} \mathrm{O}_{4} \rightarrow \mathrm{K}_{2} \mathrm{CO}_{3}+\mathrm{CO}$. This is followed, at temperature of up to $700{ }^{\circ} \mathrm{C}$, by reaction between $\mathrm{C}$ within the hydrochar and the generated potassium carbonate, which results in the etching of $\mathrm{C}$ atoms (i.e., pore formation) according to the following reaction; $\mathrm{K}_{2} \mathrm{CO}_{3}+2 \mathrm{C} \rightarrow 2 \mathrm{~K}+3 \mathrm{CO}$. The potassium carbonate can also decompose according to the following reaction; $\mathrm{K}_{2} \mathrm{CO}_{3} \rightarrow \mathrm{K}_{2} \mathrm{O}+\mathrm{CO}_{2}$. The gases from the decomposition of the carbonate cause pore formation via gasification of the hydrochar, along with the following reaction at temperature above $800{ }^{\circ} \mathrm{C} ; \mathrm{C}+\mathrm{CO}_{2} \rightarrow 2 \mathrm{CO}$. Our findings on the effects of temperature and amount of $\mathrm{PO}$ are consistent with the above mechanism, which offer an explanation for why PO is a mild activating agent compared to $\mathrm{KOH}$. It is likely that the milder nature of PO, compared to hydroxide activation, arises from the fact that PO activation occurs via oxalate decomposition to the carbonate followed by gasification reactions at high temperature, while the hydroxide reacts directly with $\mathrm{C}$ even at low temperature to generate the carbonate. Thus for $\mathrm{KOH}$ activation, the formation of the carbonate has an activating effect while for PO, the activating effect arises from decomposition of the carbonate and associated gasification processes that are accelerated at higher temperature. The series of reactions for PO activation are consistent with temperature being the more important variable as significant $\mathrm{C}$ etching requires high temperatures. In contrast, $\mathrm{KOH}$ reacts directly with the $\mathrm{C}$ in the carbonaceous precursor to generate the carbonate and $\mathrm{K}$ at lower temperature. The $\mathrm{K}$ is then intercalated into the
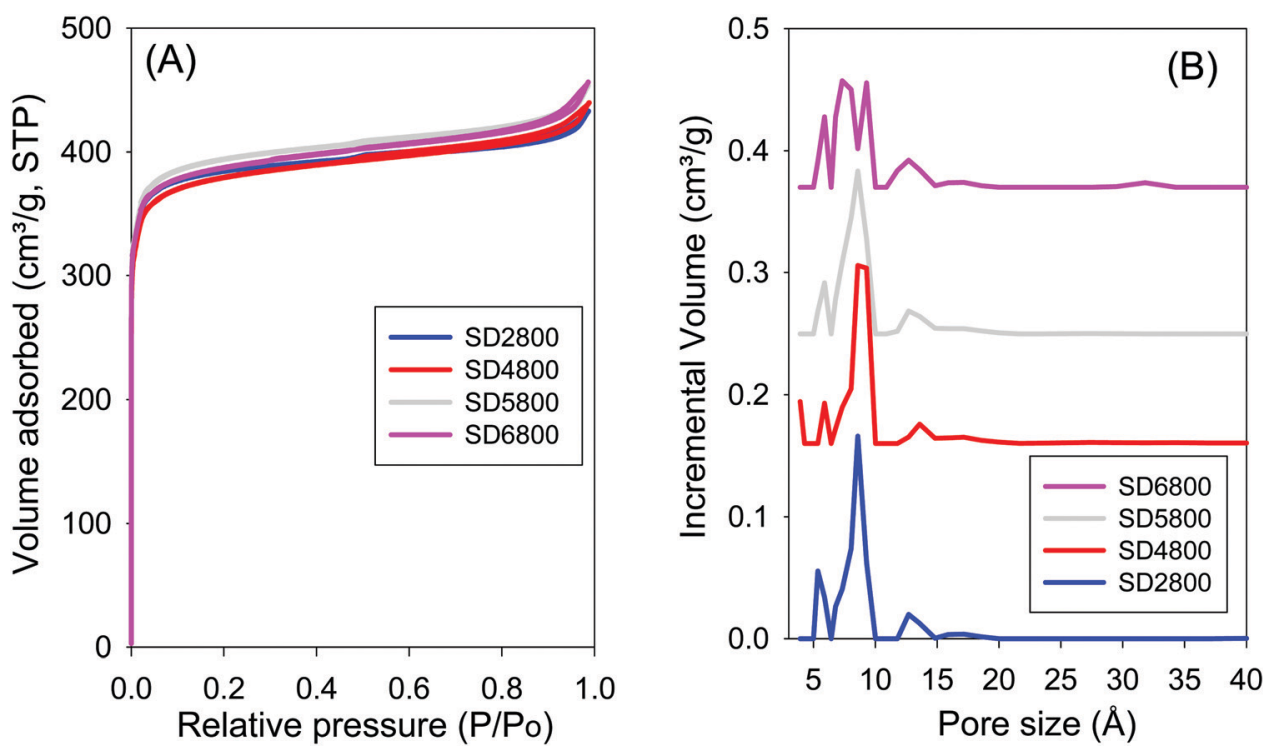

Fig. 5 Nitrogen sorption isotherms (A) and pore size distribution curves (B) for carbon samples activated at $800{ }^{\circ} \mathrm{C}$ and $\mathrm{PO} / \mathrm{SD}$ ratios of $2,4,5$ and 6 . 
carbonaceous matter causing further reactions and C etching, and gasification that lead to pore formation.

3.1.3 $\mathrm{CO}_{2}$ uptake. The $\mathrm{CO}_{2}$ uptake of the $\mathrm{SD}$ derived carbons was measured at pressure range of $0-40$ bar at $25{ }^{\circ} \mathrm{C}$. The $\mathrm{CO}_{2}$ uptake isotherms are shown in Fig. 6, and Table 2 summarises the uptake at pressure of 0.15 bar, 1 bar, and 20 bar. The $\mathrm{CO}_{2}$ uptake at 1 bar, which is often used as a measure of performance for post-combustion capture from flue gas streams from fossil fuel power stations, ${ }^{13}$ is in the range 2.6-4.3 $\mathrm{mmol} \mathrm{g}^{-1}$ for samples activated at $\mathrm{PO} / \mathrm{SD}$ ratio of 2 where the highest $\mathrm{CO}_{2}$ uptake is for sample SD2800. Thus the $\mathrm{CO}_{2}$ uptake at 1 bar rises significantly from $2.6 \mathrm{mmol} \mathrm{g}^{-1}$ for the sample activated at $600{ }^{\circ} \mathrm{C}$ to $4.3 \mathrm{mmol} \mathrm{g}^{-1}$ for the sample activated at $800{ }^{\circ} \mathrm{C}$, and then decreases to $3.4 \mathrm{mmol} \mathrm{g}^{-1}$ for sample SD2900. The uptake data suggest that the total surface area does not determine the $\mathrm{CO}_{2}$ uptake capacity at $25{ }^{\circ} \mathrm{C}$ and ambient pressure, but rather the best performance is for the sample (SD2800) with the highest micropore surface area. This is consistent with previous reports that the $\mathrm{CO}_{2}$ uptake is determined by the preponderance of narrow pores. The highest $\mathrm{CO}_{2}$ uptake at 1 bar $\left(4.3 \mathrm{mmol} \mathrm{g}{ }^{-1}\right)$ shown by sample SD2800, is comparable to that for sawdust-derived carbons activated using $\mathrm{KOH}$ as activating agent. ${ }^{20}$ However, the present PO activated carbons activated offer the advantage of simplicity in optimising the PSDs, and do not need the use of $\mathrm{KOH}$, which is highly corrosive and toxic.

At lower pressure of 0.15 bar (Fig. 6A) the $\mathrm{CO}_{2}$ uptake is in the range 1.2-1.4 $\mathrm{mmol} \mathrm{g}^{-1}$ for samples SD2600, SD2700 and SD2800, and is higher than that $\left(0.7 \mathrm{mmol} \mathrm{g}^{-1}\right)$ of sample SD2900 despite the later having the highest surface area. This trend emphasises the importance of microporosity for low pressure uptake. At higher pressure of 20 bar, the trend is reversed where the highest excess uptake of $18 \mathrm{mmol} \mathrm{g}^{-1}$ (total uptake of $19.1 \mathrm{mmol} \mathrm{g}^{-1}$ ) is for sample SD2900 compared to 4.6, 7.6, and $12 \mathrm{mmol} \mathrm{g}^{-1}$ for samples SD2600, SD2700 and SD2800, respectively. The data is consistent with the fact that the $\mathrm{CO}_{2}$ uptake at high pressure is dependent on the total surface area rather than pore size. As shown in Fig. 6B the carbons that capture high $\mathrm{CO}_{2}$ at low pressure ( $\leq 1$ bar), i.e. SD2600, SD2700 and SD2800, due to their high microporosity, approach saturation at high pressure of 20 bar and there is no significant $\mathrm{CO}_{2}$ uptake at higher pressure of up to $40 \mathrm{bar}$. On the other hand, sample SD2900, which is much less microporous, does not approach saturation even at very high pressure of $40 \mathrm{bar}$, suggesting that greater $\mathrm{CO}_{2}$ uptake is possible at higher pressure. Interestingly, therefore, the activation temperatures can be altered to tailor the textural properties of the activated carbons towards $\mathrm{CO}_{2}$ captured at either low or high pressure. ${ }^{20}$ However, it would be more desirable to achieve good high pressure uptake for carbons prepared at lower temperature, e.g., $800{ }^{\circ} \mathrm{C}$. Our data suggest that this is not possible for PO activation of sawdust hydrochar due to the mild nature of the activating agent that only achieves surface area of up to $1500 \mathrm{~m}^{2} \mathrm{~g}^{-1}$ for activation at $800{ }^{\circ} \mathrm{C}$. The $\mathrm{CO}_{2}$ uptake of samples activated at $\mathrm{PO} / \mathrm{SD}$ ratio of 4 was also investigated (Fig. S4 and Table 2). The uptake is in the range 2.9-3.8 mmol g ${ }^{-1}$ at 1 bar and $25{ }^{\circ} \mathrm{C}$. At 0.15 bar the $\mathrm{CO}_{2}$ uptake is between 0.7 and $1.2 \mathrm{mmol} \mathrm{g}^{-1}$ with the highest $\mathrm{CO}_{2}$ uptake being for sample SD4700, while sample SD4900 has the lowest uptake despite having the highest surface area. At 20 bar, the excess uptake of sample SD4900 is $17.2 \mathrm{mmol} \mathrm{g}^{-1}$ (total uptake of $18.4 \mathrm{mmol} \mathrm{g}^{-1}$ ) compared to excess uptake of 5.1, 7.6, and $11.2 \mathrm{mmol} \mathrm{g}^{-1}$, respectively, for samples SD4600, SD4700 and
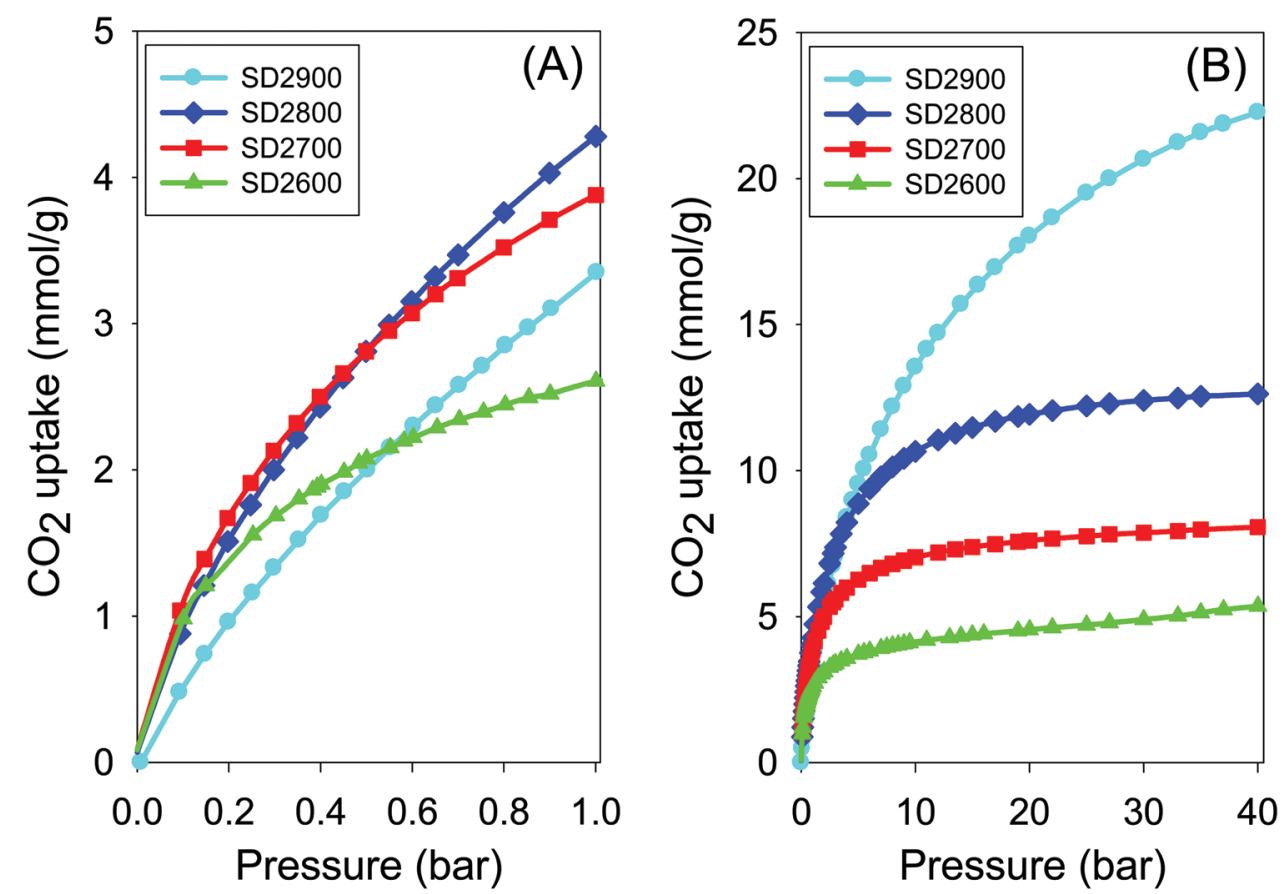

Fig. 6 Carbon dioxide uptake isotherms at $25^{\circ} \mathrm{C}$ and pressure of (A) $0-1$ bar and (B) $0-40$ bar of carbons activated at between 600 and $900{ }^{\circ} \mathrm{C}$, and $\mathrm{PO} / \mathrm{SD}$ ratio of 2 . 

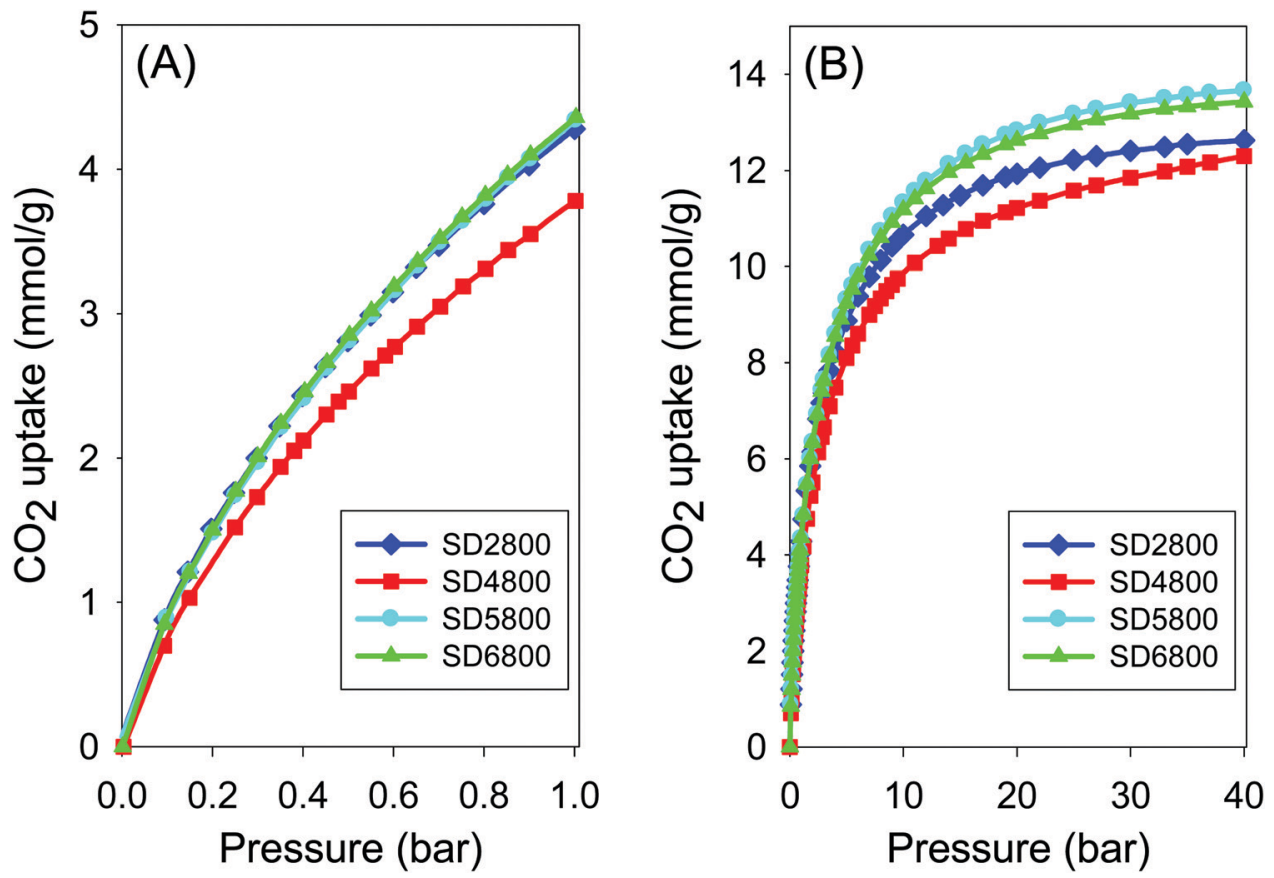

Fig. 7 Carbon dioxide uptake isotherms at $25^{\circ} \mathrm{C}$ and pressure of (A) $0-1$ bar and (B) $0-40$ bar of carbons activated at $800{ }^{\circ} \mathrm{C}$ and $\mathrm{PO} / \mathrm{SD}$ ratio of 2,4 , 5 and 6.

SD4800. This once again illustrates the critical role of the pore size and surface area in determining the $\mathrm{CO}_{2}$ uptake depending on the measurement being at either low $(\leq 1$ bar) or moderate to high ( $>20$ bar) pressure.

As discussed above, change in PO/SD ratio between 2 and 6 at $800{ }^{\circ} \mathrm{C}$ does not significantly affect the textural properties of the activated carbons. The $\mathrm{CO}_{2}$ uptake isotherms of carbons activated at $\mathrm{PO} / \mathrm{SD}$ ratio between 2 and 6 , at temperature of $800{ }^{\circ} \mathrm{C}$ are shown in Fig. 7, and the uptake values are summarised in Table 2. The $\mathrm{CO}_{2}$ uptake is in the range 3.8$4.4 \mathrm{mmol} \mathrm{g}^{-1}$ at 1 bar, where the lowest $\mathrm{CO}_{2}$ uptake is for the sample activated at ratio of 4 (SD4800) and which has slightly lower micropore surface area (Table 2) compared to samples activated at $\mathrm{PO} / \mathrm{SD}$ ratio of 2,5 or 6 . Additionally, at very low pressure of 0.15 bar, the $\mathrm{CO}_{2}$ uptake is between 1.0 and $1.2 \mathrm{mmol} \mathrm{g}^{-1}$ (Table 2). At higher pressure of $20 \mathrm{bar}$, there is a noticeable increase in the $\mathrm{CO}_{2}$ uptake for samples activated at $\mathrm{PO} / \mathrm{SD}$ ratio 5 and 6 , where the excess $\mathrm{CO}_{2}$ uptake is $12.7 \mathrm{mmol} \mathrm{g}^{-1}$ compared to 11.2 and $11.9 \mathrm{mmol} \mathrm{g}^{-1}$ for samples activated at $\mathrm{PO} / \mathrm{SD}$ ratios of 2 and 4 , respectively. This is consistent with the fact that samples activated at $\mathrm{PO} / \mathrm{SD}$ ratios of 5 or 6 have slightly higher surface area and pore volume than samples activated at ratio 2 or 4 . Our findings show that there is very limited benefit, in terms of $\mathrm{CO}_{2}$ uptake, from significantly increasing the amount of PO, and that the temperature has a far greater effect on the uptake at high pressure (20 bar and above). However, it is undesirable to have to go to $900{ }^{\circ} \mathrm{C}$ in order to achieve significant storage capacity at high pressures that simulate pre-combustion $\mathrm{CO}_{2}$ capture.

The $\mathrm{CO}_{2}$ uptake capacity of carbons activated at $\mathrm{PO} / \mathrm{SD}$ ratio of 2 or 4 and temperature ranging between 600 and $900{ }^{\circ} \mathrm{C}$, and that of the carbons activated at various $\mathrm{PO} / \mathrm{SD}$ ratios between 2 and 6 (Table 2), suggest that the activation temperature is more effective than the $\mathrm{PO} / \mathrm{SD}$ ratio in optimising or tailoring the textural properties of activated carbon for targeted $\mathrm{CO}_{2}$ uptake applications. For example, at pressure of 1 bar the $\mathrm{CO}_{2}$ uptake is $4.3 \mathrm{mmol} \mathrm{g}^{-1}$ for samples activated at $800{ }^{\circ} \mathrm{C}$, and $2.6 \mathrm{mmol} \mathrm{g}^{-1}$ for samples activated at $600{ }^{\circ} \mathrm{C}$. At low pressure of 0.15 , the $\mathrm{CO}_{2}$ uptake of samples activated at 600 and $700{ }^{\circ} \mathrm{C}$ (at either ratio 2 or 4 ) is higher than that of samples activated at $900{ }^{\circ} \mathrm{C}$. At all $\mathrm{PO} / \mathrm{SD}$ ratios explored, surface area higher than $1500 \mathrm{~m}^{2} \mathrm{~g}^{-1}$ is only achieved for activation at $900{ }^{\circ} \mathrm{C}$. This is due to the fact that $\mathrm{PO}$ is a mild activating agent compared to $\mathrm{KOH}$, which does offer activated carbons with high surface at 700 and $800{ }^{\circ} \mathrm{C}$. We therefore explored other avenues for improving the surface area of $\mathrm{PO}$ activated carbons prepared at temperatures of up to $800{ }^{\circ} \mathrm{C}$, and investigated the consequences on $\mathrm{CO}_{2}$ uptake.

\subsection{Carbons derived from polypyrrole and pre-mixed precursors}

3.2.1 Yield, elemental composition and porosity. Our results from SD derived carbons as described above, show that at activation temperature of $800{ }^{\circ} \mathrm{C}$ and below, the surface area of the resulting carbons is limited to $c a .1500 \mathrm{~m}^{2} \mathrm{~g}^{-1}$, which is consistent with previous results. ${ }^{44-51}$ Given that there is emerging evidence that the $\mathrm{O} / \mathrm{C}$ ratio of a precursor is a key consideration in the development of porosity, with high $\mathrm{O} / \mathrm{C}$ ratio favouring generation of greater surface area and pore volume, ${ }^{54}$ we reasoned that the use of a precursor that has higher nominal $\mathrm{O} / \mathrm{C}$ ratio (compared to sawdust hydrochar) would allow an investigation of the effect of $\mathrm{O} / \mathrm{C}$ ratio on $\mathrm{PO}$ 
activation and potentially enable tailoring of the surface area to values above $1500 \mathrm{~m}^{2} \mathrm{~g}^{-1}$ even for activation at $800{ }^{\circ} \mathrm{C}$. Based on the elemental composition data in Table 1 , the $\mathrm{O} / \mathrm{C}$ ratio of sawdust hydrochar is 0.48 . We therefore selected to explore polypyrrole (Ppy), which has a higher $\mathrm{O} / \mathrm{C}$ ratio of $0.67,{ }^{54}$ as alternative starting material both singly and in combination with sawdust hydrochar in the form of pre-mixed precursors. Our findings for SD derived carbons show that a $\mathrm{PO} / \mathrm{SD}$ ratio of 2 achieves the full range of porosity depending on the activation temperature. For this reason we only further explored carbons prepared from polypyrrole and pre-mixed precursors at $\mathrm{PO} /$ precursor ratio of 2 .

We, firstly, performed PO activation of Ppy to explore our hypothesis that it would generate activated carbons with higher surface area than sawdust hydrochar, and also to confirm that Ppy acts as a true carbonaceous precursor rather than as an activation enhancer as noted in the case of melamine. ${ }^{46,47}$ Activation of polypyrrole at $\mathrm{PO} / \mathrm{Ppy}$ ratio of 2 and temperature of between 600 and $900{ }^{\circ} \mathrm{C}$, offers activated carbon yields of 21-43 wt\% (Table S1, ESI $\dagger$ ), which are comparable to the yield from sawdust hydrochar (Table 1 and Table S1, ESI $\dagger$ ). The $\mathrm{C}, \mathrm{H}$, $\mathrm{N}$ and $\mathrm{O}$ content, as a function of activation temperature, shows a trend similar to that of sawdust hydrochar, with $\mathrm{C}$ increasing while $\mathrm{H}, \mathrm{N}$ and $\mathrm{O}$ decrease significantly (Table S1, ESI $\dagger$ ). The porosity of the resulting carbons (Fig. S5, ESI $\dagger$ ) in much higher than that of the SD derived carbons (Table 3). The surface area of Ppy derived samples activated at $800{ }^{\circ} \mathrm{C}$ is between $800 \mathrm{~m}^{2} \mathrm{~g}^{-1}$ and $2750 \mathrm{~m}^{2} \mathrm{~g}^{-1}$ compared to $500 \mathrm{~m}^{2} \mathrm{~g}^{-1}$ to $1500 \mathrm{~m}^{2} \mathrm{~g}^{-1}$ for SD derived carbons. The pore volume $\left(0.4\right.$ to $\left.1.5 \mathrm{~cm}^{3} \mathrm{~g}^{-1}\right)$ is also higher than that of SD-derived samples $\left(0.3-1.3 \mathrm{~cm}^{3} \mathrm{~g}^{-1}\right)$. The Ppy derived carbons prepared at 800 or $900{ }^{\circ} \mathrm{C}$ have a much greater proportion of mesopores (Fig. S5 and Table 3, ESI $\dagger$ ) compared to equivalent SD derived carbons. This is the expected trend based on the $\mathrm{O} / \mathrm{C}$ ratio of sawdust hydrochar and polypyrrole, and starts to validate our hypothesis on the role played by the $\mathrm{O} / \mathrm{C}$ ratio of the precursor in $\mathrm{PO}$ activation. We note that the surface area and pore volume observed for the PO activation of polypyrrole are, as expected, lower than those observed for $\mathrm{KOH}$ activation of polypyrrole under similar conditions. $^{8,17,38,54}$

PO activation was performed for pre-mixed precursors containing Ppy and SD at various ratios, i.e., 1:2, 1:1 or 2:1 Ppy: SD ratio. The selected Ppy:SD ratios offer a scenario where the amount of Ppy in the pre-mixed precursors is increased in a systematic manner such that it is possible to explore the effect of such an increase on the resulting activated carbons, and to relate it to observations for single PO activation of SD or Ppy. The yield of activated carbon from PO activation of all premixed precursors, regardless of their composition, is similar to that from single activation of SD or Ppy (Table S1, ESI) $\dagger$ The trend in $\mathrm{C}, \mathrm{H}, \mathrm{N}$ and $\mathrm{O}$ content, as a function of activation temperature, is similar to that observed for single use of SD or $\mathrm{Ppy}$, i.e., $\mathrm{C}$ increases while $\mathrm{H}, \mathrm{N}$ and $\mathrm{O}$ decrease significantly (Table S1, ESI $\dagger$ ). As expected, the amount of $\mathrm{N}$ is generally higher for activated carbons prepared from pre-mixed precursors with greater amounts of Ppy, especially for activation at 600 and $700{ }^{\circ} \mathrm{C}$. It is interesting to note that the surface area and pore volume of the carbons prepared from pre-mixed precursors is generally higher than that of equivalent samples prepared from SD but lower that of samples from Ppy. Thus, in terms of the porosity generated, carbons prepared from SD and Ppy can be considered to be end members of a series with SD at the bottom and Ppy at the top. This is especially the case for samples activated at 700 and $800{ }^{\circ} \mathrm{C}$. For example, the surface area of samples activated at $700{ }^{\circ} \mathrm{C}$ rises, with increasing amounts of Ppy in the precursor, in the order; SD $\left(893 \mathrm{~m}^{2} \mathrm{~g}^{-1}\right)<$ Ppy-SD(1-2)

Table 3 Textural properties of carbons prepared at PO/precursor ratio of 2 from sawdust hydrochar (SD), polypyrrole (Ppy), and pre-mixed precursors containing sawdust hydrochar and polypyrrole (Ppy-SD)

\begin{tabular}{|c|c|c|c|c|c|c|c|}
\hline Sample & $\begin{array}{l}\text { Surface area }{ }^{a} \\
\left(\mathrm{~m}^{2} \mathrm{~g}^{-1}\right)\end{array}$ & $\% \mu \mathrm{SA}$ & $\begin{array}{l}\text { Pore volume } \\
\left(\mathrm{cm}^{3} \mathrm{~g}^{-1}\right)\end{array}$ & $\begin{array}{l}\text { Pore size } \\
(\AA)\end{array}$ & \multicolumn{3}{|c|}{$\underline{\mathrm{CO}_{2}}$ uptake $\left(\mathrm{mmol} \mathrm{g}^{-1}\right)$ at $25^{\circ} \mathrm{C}$} \\
\hline SD2600 & $506(411)$ & 81 & $0.27(0.16)$ & $6 / 8$ & 1.2 & 2.6 & $4.6(4.8)$ \\
\hline SD2800 & $1463(1311)$ & 90 & $0.67(0.53)$ & $6 / 8 / 13$ & 1.2 & 4.3 & $11.9(12.5)$ \\
\hline SD2900 & $2350(800)$ & 34 & $1.27(0.32)$ & $6 / 8 / 12 / 27$ & 0.7 & 3.4 & $18.0(19.1)$ \\
\hline Ppy-SD(1-2)2600 & 678 (591) & 87 & $0.32(0.24)$ & $6 / 8$ & 1.4 & 3.3 & $5.9(6.2)$ \\
\hline Ppy-SD(1-1)2600 & $612(527)$ & 86 & $0.29(0.21)$ & $6 / 8$ & 1.2 & 2.9 & $5.3(5.6)$ \\
\hline Ppy-SD(1-1)2700 & 1612 (1387) & 86 & $0.73(0.56)$ & $6 / 8 / 9 / 13$ & 1.2 & 4.1 & $12.5(13.2)$ \\
\hline Ppy-SD(1-1)2800 & 2291 (1688) & 74 & $1.06(0.67)$ & $6 / 9 / 12 / 16 / 20$ & 0.8 & 3.7 & $17.0(18.0)$ \\
\hline Ppy-SD(1-1)2900 & 2601 (273) & 11 & $1.67(0.12)$ & $6 / 8 / 11 / 27 / 34$ & 0.5 & 2.5 & $18.0(19.5)$ \\
\hline Ppy-SD(2-1)2600 & $655(569)$ & 87 & $0.31(0.23)$ & 6/7/9 & 1.3 & 3.1 & $5.6(5.9)$ \\
\hline Ppy-SD(2-1)2700 & 1665 (1435) & 86 & $0.75(0.57)$ & $6 / 9 / 13$ & 1.1 & 4.0 & $13.5(14.2)$ \\
\hline Ppy2900 & $2542(263)$ & 10 & $1.45(0.10)$ & $6 / 8 / 11 / 21 / 26$ & 0.5 & 2.5 & $18.5(19.8)$ \\
\hline
\end{tabular}

${ }^{a}$ Values in parenthesis are micropore surface area. ${ }^{b}$ Values in parenthesis are micropore volume. ${ }^{c}$ Values in parenthesis are total $\mathrm{CO}_{2}$ uptake. 
$\left(1174 \mathrm{~m}^{2} \mathrm{~g}^{-1}\right)<\operatorname{Ppy}-\mathrm{SD}(1-1)\left(1612 \mathrm{~m}^{2} \mathrm{~g}^{-1}\right)<\operatorname{Ppy}-\mathrm{SD}(2-1)$ $\left(1665 \mathrm{~m}^{2} \mathrm{~g}^{-1}\right)<$ Ppy $\left(1779 \mathrm{~m}^{2} \mathrm{~g}^{-1}\right)$. For activation at $800{ }^{\circ} \mathrm{C}$, a similar order is observed as follows; $\mathrm{SD}\left(1463 \mathrm{~m}^{2} \mathrm{~g}^{-1}\right)<\operatorname{Ppy}-\mathrm{SD}(1-2)$ $\left(2042 \mathrm{~m}^{2} \mathrm{~g}^{-1}\right)<\operatorname{Ppy}-\mathrm{SD}(1-1)\left(2291 \mathrm{~m}^{2} \mathrm{~g}^{-1}\right)<\operatorname{Ppy}-\mathrm{SD}(2-1)$ $\left(2423 \mathrm{~m}^{2} \mathrm{~g}^{-1}\right)<$ Ppy $\left(2747 \mathrm{~m}^{2} \mathrm{~g}^{-1}\right)$. Similar trends are observed for the pore volume. Samples activated at $600{ }^{\circ} \mathrm{C}$ also show similar trends but it should be noted that the level of activation at $600{ }^{\circ} \mathrm{C}$ is quite low. ${ }^{46}$ Sevilla and co-workers found that heating sawdust hydrochar (with no activating agent) at between 500 and $800{ }^{\circ} \mathrm{C}$ generates carbons with surface area of up to $420 \mathrm{~m}^{2} \mathrm{~g}^{-1} \cdot{ }^{46}$ The surface area of carbons derived from SD containing precursors activated at $600{ }^{\circ} \mathrm{C}$ is 500 to $650 \mathrm{~m}^{2} \mathrm{~g}^{-1}$, which means that PO achieves only limited activation. This low level of activation may explain why a clear step-wise trend is not observed as is the case for activation at 700 and $800{ }^{\circ} \mathrm{C}$. For activation at $900{ }^{\circ} \mathrm{C}$, a step-wise rise in surface area is observed with increase in Ppy content in the precursor except for a decrease for sample Ppy2900, which we attribute to over activation. Such over activation is known to reduce surface area, ${ }^{21}$ and is consistent with polypyrrole having a relatively high $\mathrm{O} / \mathrm{C}$ ratio, which means that it is more easily activated and thus likely to suffer from over activation at $900{ }^{\circ} \mathrm{C} .{ }^{54}$

It is also clear from the porosity data (Table 3 ) and nitrogen sorption isotherms and pore size distribution curves of the samples prepared from pre-mixed precursors (Fig. S6-S8, ESI $\dagger$ ) that there is a shift towards greater mesoporosity as the amount of Ppy in the precursor increases. This shift towards mesoporosity is also evident from the variations in proportion of surface area that arises from micropores, and the pore size maxima values summarised in Table 3. Our results show that by exploring $\mathrm{PO}$ activation of pre-mixed precursors, which are made up of carbonaceous matter (SD and Ppy) that is known to respond differently to similar levels of activation, we are able to modulate the porosity of the resulting carbons in a systematic manner and achieve higher values of surface area and pore volume. This approach can enable optimising of the porosity to generate microporous or mesoporous carbons to match specific applications, and we according explored the carbons for $\mathrm{CO}_{2}$ storage.

3.2.2 $\mathrm{CO}_{2}$ uptake. The $\mathrm{CO}_{2}$ uptake of carbons derived from Ppy (Fig. S9, ESI $\dagger$ ) and the pre-mixed precursors (Fig. S10-S12, ESI $\dagger$ ) is summarised and compared to that of equivalent SD derived carbons in Table 3. The $\mathrm{CO}_{2}$ uptake data reveals clear trends that can be related to changes in porosity as determined by the nature of the precursor. At very low pressure $(0.15 \mathrm{bar})$, all carbons activated at $600{ }^{\circ} \mathrm{C}$ have similar uptake of 1.2-1.4 $\mathrm{mmol} \mathrm{g}^{-1}$. Uptake at such low pressure is determined by the presence of micropores of size 6-8 $\AA$ and high level of microporosity. In this regard, all the carbons activated at $600{ }^{\circ} \mathrm{C}$, regardless of the precursor, are similar with between 81 and $87 \%$ of surface area arising from micropores (Table 3). For activation at $700{ }^{\circ} \mathrm{C}\left(1-1.4 \mathrm{mmol} \mathrm{g}^{-1}\right)$ and $800{ }^{\circ} \mathrm{C}$ (0.7-1.2 $\left.\mathrm{mmol} \mathrm{g}^{-1}\right)$, there is greater variation in uptake at 0.15 bar. This is due to the fact that although the level of microporosity does not vary significantly depending on the precursor, there is a clear trend where greater amounts of Ppy in the precursor results in larger micropores, which has the effect of lowering the $\mathrm{CO}_{2}$ uptake (Table 3 and Fig. S10-S12, ESI $\dagger$ ). Samples activated at $900{ }^{\circ} \mathrm{C}$ have the lowest $\mathrm{CO}_{2}$ uptake at $0.15 \mathrm{bar}\left(0.5-0.7 \mathrm{mmol} \mathrm{g}^{-1}\right)$ regardless of the precursor due to their much lower microporosity and larger micropores and mesopores. At pressure of $1 \mathrm{bar}$, the uptake of samples prepared at $600{ }^{\circ} \mathrm{C}$ is related to the surface area since all the carbons have similar levels of microporosity and possess pores of comparable size. The uptake therefore increases from $2.6 \mathrm{mmol} \mathrm{g}^{-1}$ for SD2600, which has the lowest surface area $\left(506 \mathrm{~m}^{2} \mathrm{~g}^{-1}\right)$ to $3.5 \mathrm{mmol} \mathrm{g}^{-1}$ for Ppy 2600 with surface area of $812 \mathrm{~m}^{2} \mathrm{~g}^{-1}$. Samples activated at $700{ }^{\circ} \mathrm{C}$ have uptake within the relatively narrow range of $3.8-4.1 \mathrm{mmol} \mathrm{g}^{-1}$, which we ascribe to similar levels of microporosity. For activation at $800{ }^{\circ} \mathrm{C}$, it is interesting to note that all carbons retain high $\mathrm{CO}_{2}$ uptake in the range $3.3-4.3 \mathrm{mmol} \mathrm{g}^{-1}$, with the lower end exhibited by samples with higher mesoporosity that are derived from precursors with greater amounts of Ppy. The uptake at 1 bar is lowest $\left(2.5-3.4 \mathrm{mmol} \mathrm{g}^{-1}\right)$ for samples activated at $900{ }^{\circ} \mathrm{C}$ due their far higher levels of mesoporosity.

The much higher porosity of carbons derived from Ppy and pre-mixed precursor has a much greater effect on the $\mathrm{CO}_{2}$ uptake at higher pressure ( $>20$ bar). As shown in Tables 2 and 3, the excess $\mathrm{CO}_{2}$ uptake at 20 bar of SD derived carbons reaches a maximum of $c a .12 .9 \mathrm{mmol} \mathrm{g}^{-1}$ (total uptake of $13.5 \mathrm{mmol} \mathrm{g}^{-1}$ ), and for samples prepared at PO/SD ratio of 2, the maximum is 11.9 and $12.5 \mathrm{mmol} \mathrm{g}^{-1}$, respectively, for excess and total uptake. Carbons activated at $900{ }^{\circ} \mathrm{C}$ reach higher uptake, but as stated above it is desirable to avoid such a high activation temperature. The Ppy2800 sample achieves very high total $\mathrm{CO}_{2}$ uptake of $20.3 \mathrm{mmol} \mathrm{g}^{-1}$ at $20 \mathrm{bar}$, which is $60 \%$ higher than that $\left(12.5 \mathrm{mmol} \mathrm{g}^{-1}\right)$ of the equivalent SD derived carbon (SD2800). The equivalent pre-mixed precursor samples also achieve total uptake of between 17.5 and $18.8 \mathrm{mmol} \mathrm{g}^{-1}$. Our findings, therefore, show that by careful choice of precursor, it is possible to prepare carbons highly suited for medium to high pressure $\mathrm{CO}_{2}$ storage via mild $\mathrm{PO}$ activation.

Carbons that have excellent medium to high pressure $\mathrm{CO}_{2}$ uptake are potentially very well suited for $\mathrm{CO}_{2}$ separation from $\mathrm{H}_{2}$ before the latter is used as fuel for power stations that operate the Integrated Gasification Combined Cycle (IGCC). The separation of the gases in fuel streams with $\mathrm{CO}_{2}$ concentration of $c a .40 \mathrm{vol} \%$ (with $\mathrm{H}_{2}$ at $60 \mathrm{vol} \%$ ) occurs at a pressure of up to 40 bar, which means that the $\mathrm{CO}_{2}$ partial pressure in the stream is up to $c a .16$ bar. The $\mathrm{CO}_{2}$ is typically removed via pressure swing adsorption (PSA) processes, wherein capture takes place at the fuel stream pressure of up to $40 \mathrm{bar}$ (meaning $\mathrm{CO}_{2}$ partial pressure of $16 \mathrm{bar}$ ) followed by desorption at $1 \mathrm{bar}$ (i.e., $\mathrm{CO}_{2}$ partial pressure of 0.4 bar). The most important indicator of performance for $\mathrm{CO}_{2}$ capture in such precombustion scenarios is the PSA working capacity, which is the difference in storage capacity between the adsorption and desorption pressure. We therefore determined the PSA working capacity of the present carbons for adsorption pressure of 5 to 40 bar, which is typical for PSA systems used in pre-combustion $\mathrm{CO}_{2}$ for a $60 \% \mathrm{H}_{2}: 40 \% \mathrm{CO}_{2}$ gas stream. The excess PSA working capacity for SD derived carbons, shown in Fig. 8, is dependent 

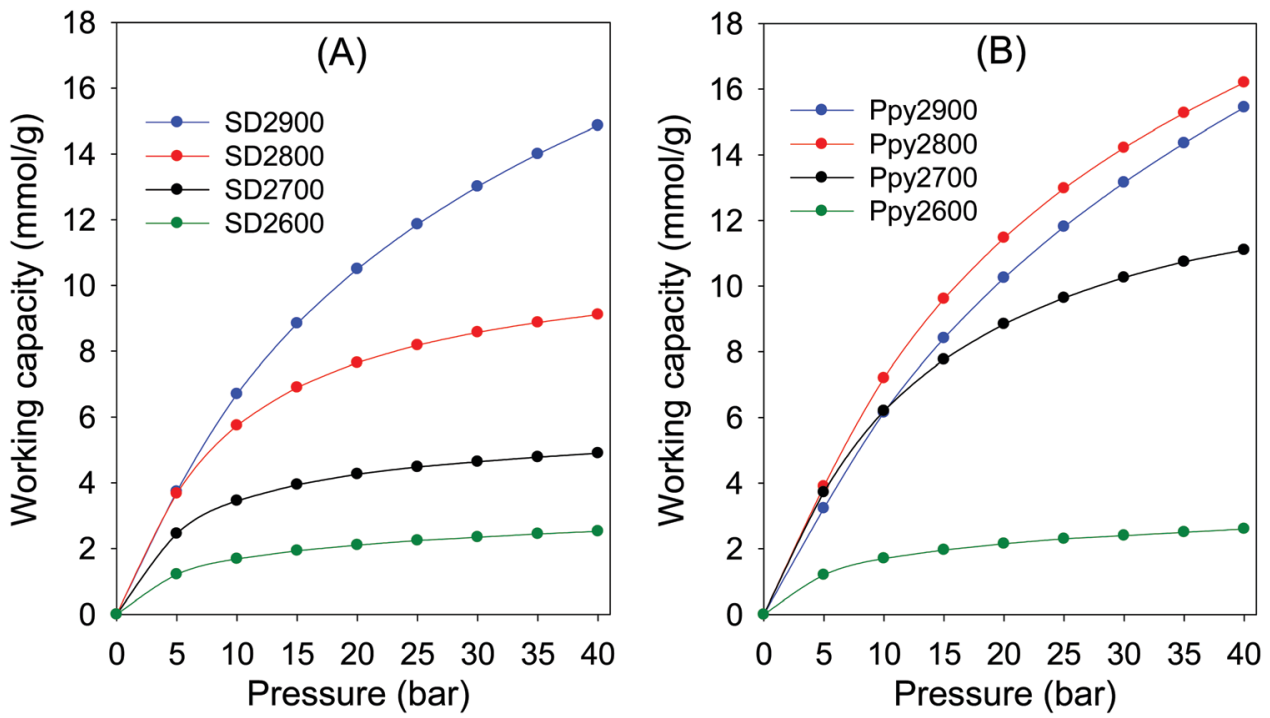

Fig. 8 Excess pressure swing adsorption (PSA) $\mathrm{CO}_{2}$ working capacity for a $60: 40 \mathrm{H}_{2} / \mathrm{CO}_{2}$ mixture for (A) sawdust hydrochar (SD) or polypyrrole (Ppy) derived carbons activated at between 600 and $900{ }^{\circ} \mathrm{C}$, and PO/precursor ratio of 2 .

on activation temperature, and while it is low for both sample SD2600 (1.2-2.5 $\left.\mathrm{mmol} \mathrm{g}^{-1}\right)$ and SD2700 (2.5-4.9 $\left.\mathrm{mmol} \mathrm{g}^{-1}\right)$, in the adsorption pressure of 5 to 40 bar, it increases for sample SD2800 (3.7-9.0 $\left.\mathrm{mmol} \mathrm{g}^{-1}\right)$, and is much higher for SD2900 (3.7-14.9 $\left.\mathrm{mmol} \mathrm{g}^{-1}\right)$. Furthermore, due to their higher pore volume, sample SD2800 and SD2900, show significant difference between excess and total PSA working capacity, especially for higher adsorption pressure (Fig. S13, ESI $\dagger$ ). The PSA working capacity for the SD derived carbons is clearly related to porosity meaning that attractive working capacity is only observed for the sample activated at the highest temperature $\left(900{ }^{\circ} \mathrm{C}\right)$. On the other hand, Ppy derived carbons prepared at lower activation temperature exhibit good to excellent PSA working capacity (Fig. 8B and Fig. S14, ESI $\dagger$ ). The excess working capacity for Ppy2600 $\left(1.2-2.6 \mathrm{mmol} \mathrm{g}^{-1}\right)$ is similar to that of SD2600, while it is much higher (Fig. S15, ESI $\dagger$ ) for Ppy2700 (3.7-12 $\left.\mathrm{mmol} \mathrm{g}^{-1}\right)$, Ppy2800 (3.9-16.2 $\left.\mathrm{mmol} \mathrm{g}^{-1}\right)$, and Ppy2900 $\left(3.2-15.4 \mathrm{mmol} \mathrm{g}^{-1}\right)$. A similar trend is observed for the total PSA working capacity (Fig. S16, ESI $\dagger$ ).

As shown in Fig. 9, the carbons prepared from pre-mixed precursors at activation temperature of $800{ }^{\circ} \mathrm{C}$ exhibit excellent PSA working capacity, and in general outperform those prepared at $900{ }^{\circ} \mathrm{C}$ due to a better mix of microporosity and mesoporosity. The PSA excess working capacity of carbons derived from pre-mixed precursor at $800{ }^{\circ} \mathrm{C}$ (up to $15 \mathrm{mmol} \mathrm{g}^{-1}$ at adsorption pressure of $40 \mathrm{bar}$ ), is much higher than that of the equivalent SD derived sample, which only achieves $9 \mathrm{mmol} \mathrm{g}^{-1}$ ). Our findings, and particularly the clear role played by the temperature and type of precursor and consequences on applications such as $\mathrm{CO}_{2}$ storage, offer new insights beyond what is currently reported in the literature on the practicalities of using mild activating agents such as PO. To get a fuller picture of the performance of the present PO activated carbons, we compared their PSA working capacity to porous materials with much higher surface area, namely,

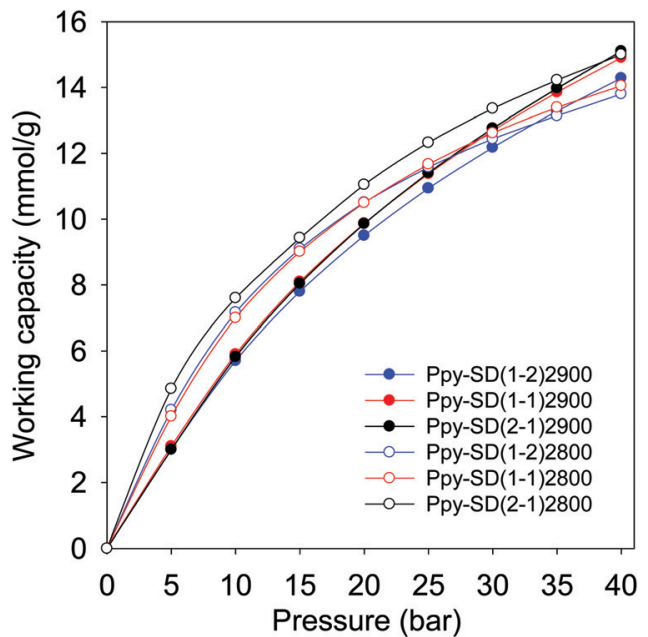

Fig. 9 Excess pressure swing adsorption (PSA) $\mathrm{CO}_{2}$ working capacity for a $60: 40 \mathrm{H}_{2} / \mathrm{CO}_{2}$ mixture for carbons derived from pre-mixed precursors containing polypyrrole (Ppy) and sawdust hydrochar (SD) at various ratios. The carbons were prepared at activation temperature of 800 or $900{ }^{\circ} \mathrm{C}$, and $\mathrm{PO} /$ precursor ratio of 2 .

a carbon (G-2.7-2) prepared via activation with $\mathrm{PO}$ and melamine, ${ }^{47}$ and metal organic frameworks $(\mathrm{Nu}-100$ and MOF210) ${ }^{62,63}$ These porous materials are reported to have high $\mathrm{CO}_{2}$ uptake at high pressure due to their large surface area, and are claimed to be potentially useful for pre-combustion $\mathrm{CO}_{2}$ capture. The working capacity of the best performing PO activated carbons (Ppy2800 and Ppy-SD(2-1)2800) is comparable or better than these benchmark materials (Fig. S17, ESI $\dagger$ ). The PO activated carbons offer better PSA working capacity than NU-100 and MOF210 despite the later having nearly twice the surface area. Furthermore, the PO activated carbons are expected to have higher volumetric PSA working capacity than the MOFs given that, unlike activated carbons, the packing 
density of high surface area MOFs tends to be low and they lose their uptake capacity when compacted.

\section{Conclusion}

We have shown that a less corrosive and toxic activating agent such as potassium oxalate (PO) can be successfully applied in a targeted manner to generate activated carbons from a range of precursors, including sawdust hydrochar, polypyrrole, or pre-mixed precursors that contain both biomass hydrochar and polypyrrole. By careful choice of activation conditions, it is possible to obtain activated carbons, with surface area of up to $2740 \mathrm{~m}^{2} \mathrm{~g}^{-1}$ and pore volume up to $1.7 \mathrm{~cm}^{3} \mathrm{~g}^{-1}$, which can be either highly microporous or highly mesoporous. The most important variables in controlling the porosity are the activation temperature and type of precursor based on their $\mathrm{O} / \mathrm{C}$ ratio. Unlike what is observed for one of the most commonly used activating agents, $\mathrm{KOH}$, changes in the $\mathrm{PO} /$ precursor ratio, within the range of 2-6, has no significant influence on the porosity of the PO activated carbons. This, therefore, unusually means that a relatively low $\mathrm{PO} /$ precursor ratio of 2 , along with temperature variations, can be applied to generate a suite of carbons with the full range of porosity. This scenario offers a more eco-friendly and sustainable activation process in terms of amount of activating agent required, and also enables easier control of the porosity by simple choice of one variable, namely, activation temperature. We show that, due to their inherent $\mathrm{O} / \mathrm{C}$ ratio, $\mathrm{PO}$ activation of sawdust hydrochar at temperatures up to $800{ }^{\circ} \mathrm{C}$ does not generate carbons with surface area higher than $1500 \mathrm{~m}^{2} \mathrm{~g}^{-1},{ }^{46-51}$ while use of polypyrrole does achieve carbons with surface area up to $2700 \mathrm{~m}^{2} \mathrm{~g}^{-1}$ under similar activation conditions. Furthermore, the surface area and pore volume of the carbons prepared from pre-mixed precursors containing sawdust hydrochar and polypyrrole is higher than that of equivalent samples prepared from sawdust hydrochar but lower that of samples from polypyrrole. Thus, interestingly, in terms of the porosity generated, carbons prepared from sawdust hydrochar and polypyrrole may be considered to be end members of a series with the former at the bottom and latter at the top. It is, therefore, possible to direct the porosity of the activated carbons towards pores channels of size 6 to $8 \AA$ that are efficient for $\mathrm{CO}_{2}$ storage at low pressure conditions that mimic post-combustion $\mathrm{CO}_{2}$ capture. At $25{ }^{\circ} \mathrm{C}$, the carbons can store up to 1.4 and $4.4 \mathrm{mmol} \mathrm{g}^{-1}$ of $\mathrm{CO}_{2}$ at 0.15 bar and $1 \mathrm{bar}$, respectively. The micropore/mesopore mix of the carbons can also be controlled towards greater mesoporosity, which is favourable for moderate to high pressure $\mathrm{CO}_{2}$ storage conditions that mimic pre-combustion capture. At $25{ }^{\circ} \mathrm{C}$, the carbons can store up to $20.3 \mathrm{mmol} \mathrm{g}^{-1}$ at $20 \mathrm{bar}$ and $30.1 \mathrm{mmol} \mathrm{g}^{-1}$ at 40 bar. At a maximum activation temperature of $800{ }^{\circ} \mathrm{C}$, the porosity of the carbons can be tailored so as to optimise pre-combustion $\mathrm{CO}_{2}$ capture via pressure swing adsorption (PSA) processes at adsorption pressure of up to 40 bar and desorption at 1 bar, from gas mixtures (e.g., $60: 40 \mathrm{H}_{2} / \mathrm{CO}_{2}$ ) where the carbons achieve excellent working capacity that is higher than that of benchmark porous materials that have much larger surface area.

\section{Conflicts of interest}

There are no conflicts to declare.

\section{Acknowledgements}

We thank the government of Iraq for funding a PhD studentship for Abdulsalam Aljumialy. RM thanks the Royal Society for a Research Grant, and for a Royal Society Wolfson Research Merit Award.

\section{References}

1 L. Wei and G. Yushin, Nano Energy, 2012, 1, 552.

2 M. Sevilla and R. Mokaya, Energy Environ. Sci., 2014, 7, 1250.

3 Y. X. Xia, Z. X. Yang and Y. Zhu, J. Mater. Chem. A, 2013, 1, 9365.

4 M. M. Titirici, R. J. White, C. Falco and M. Sevilla, Energy Environ. Sci., 2012, 5, 6796.

5 L. Schlapbach and A. Züttel, Nature, 2001, 414, 353.

6 Y. Zhu, S. Murali, M. D. Stoller, K. J. Ganesh, W. Cai, P. J. Ferreira, A. Pirkle, R. M. Wallace, K. A. Cychosz, M. Thommes, D. Su, E. A. Stach and R. S. Ruoff, Science, 2011, 332, 1537.

7 J. C. Wang and S. Kaskel, J. Mater. Chem., 2012, 22, 23710.

8 M. Sevilla, A. B. Fuertes and R. Mokaya, Energy Environ. Sci., 2011, 3, 1400.

9 Z. Yang, Y. Xia and R. Mokaya, J. Am. Chem. Soc., 2007, 129, 1673.

10 T. S. Blankenship, N. Balahmar and R. Mokaya, Nat. Commun., 2017, 8, 1545.

11 E. Masika and R. Mokaya, Energy Environ. Sci., 2014, 7, 427.

12 L. Wei, M. Sevilla, A. B. Fuertes, R. Mokaya and G. Yushin, Adv. Energy Mater., 2011, 1, 356.

13 H. M. Coromina, D. A. Walsh and R. Mokaya, J. Mater. Chem. A, 2016, 4, 280.

14 M. Sevilla and A. B. Fuertes, Energy Environ. Sci., 2011, 4, 1765 .

15 M. Sevilla, W. Sangchoom, N. Balahmar, A. B. Fuertes and R. Mokaya, ACS Sustainable Chem. Eng., 2016, 4, 4710.

16 W. Sangchoom and R. Mokaya, ACS Sustainable Chem. Eng., 2015, 3, 1658.

17 N. Balahmar, A. C. Mitchell and R. Mokaya, Adv. Energy Mater., 2015, 5, 1500867.

18 C. Robertson and R. Mokaya, Microporous Mesoporous Mater., 2013, 179, 151.

19 E. A. Hirst, A. Taylor and R. Mokaya, J. Mater. Chem. A, 2017, 6, 12393.

20 N. Balahmar, A. Al-Jumialy and R. Mokaya, J. Mater. Chem. A, 2017, 5, 12330.

21 T. S. Blankenship and R. Mokaya, Energy Environ. Sci., 2017, 10, 2552. 
22 J.-J. Hwang, Renewable Sustainable Energy Rev., 2013, 19, 220.

23 S. Choi, J. H. Drese and C. W. Jones, ChemSusChem, 2009, 2, 796.

24 K. B. Tokarska and N. P. Gillett, Nat. Clim. Change, 2018, 8, 296.

25 R. J. Millar, J. S. Fuglestvedt, P. Friedlingstein, J. Rogelj, M. J. Grubb, H. D. Matthews, R. B. Skeie, P. M. Forster, D. J. Frame and A. R. Andmyles, Nat. Geosci., 2017, 10, 741.

26 B. Adeniran, E. Masika and R. Mokaya, J. Mater. Chem. A, 2014, 2, 14696.

27 Z. J. Zhang, Z. Z. Yao, S. C. Xiang and B. L. Chen, Energy Environ. Sci., 2014, 7, 2868.

28 B. Adeniran and R. Mokaya, Chem. Mater., 2016, 28, 994.

29 J. P. Marco-Lozar, M. Kunowsky, F. Suarez-Garcia, J. D. Carruthers and A. Linares-Solano, Energy Environ. Sci., 2012, 5, 9833.

30 E. Haffner-Staton, N. Balahmar and R. Mokaya, J. Mater. Chem. A, 2016, 4, 13324.

31 M. R. Hudson, Q. L. Queen, J. A. Mason, D. W. Fickel, R. F. Lobo and C. M. Brown, J. Am. Chem. Soc., 2012, 134, 1970.

32 Y. Xia, R. Mokaya, G. S. Walker and Y. Q. Zhu, Adv. Energy Mater., 2011, 1, 678.

33 Z. Zhang, J. Zhou, W. Xing, Q. Xue, Z. Yan, S. Zhuo and S. Z. Qiao, Phys. Chem. Chem. Phys., 2013, 15, 2523.

34 B. Adeniran and R. Mokaya, J. Mater. Chem. A, 2015, 3, 5148.

35 N. P. Wickramaratne and M. Jaroniec, J. Mater. Chem. A, 2013, 1, 112.

36 A. Wahby, J. M. Ramos-Fernandez, M. Martnez-Escandell, A. Sepulveda-Escribano, J. Silvestre-Albero and F. RodriguezReinoso, ChemSusChem, 2010, 3, 974.

37 N. P. Wickramaratne and M. Jaroniec, ACS Appl. Mater. Interfaces, 2013, 5, 1849.

38 B. Adeniran and R. Mokaya, Nano Energy, 2015, 16, 173.

39 M. Sevilla, A. B. Fuertes and R. Mokaya, Int. J. Hydrogen Energy, 2011, 36, 15658.

40 M. Sevilla, R. Mokaya and A. B. Fuertes, Energy Environ. Sci., 2011, 4, 2930.

41 M. Plaza, A. González, J. Pis, F. Rubiera and C. Pevida, Appl. Energy, 2014, 114, 551.

42 C. Moreno-Castilla, F. Carrasco-Marín, M. V. Lopez-Ramon and M. A. Alvarez-Merino, Carbon, 2001, 39, 1415.
43 A. R. Satayeva, C. A. Howell, A. V. Korobeinyk, J. Jandosov, V. J. Inglezakis, Z. A. Mansurov and S. V. Mikhalovsky, Sci. Total Environ., 2018, 630, 1237.

44 Y. Chen, W. Chen, B. Huang and M. Huang, Chem. Eng. Res. Des., 2013, 91, 1783.

45 J. Ludwinowicz and M. Jaroniec, Carbon, 2015, 82, 297.

46 M. Sevilla, G. A. Ferrero and A. B. Fuertes, Carbon, 2017, 114, 50.

47 M. Sevilla, A. M. Al-Jumialy, A. B. Fuertes and R. Mokaya, ACS Appl. Mater. Interfaces, 2018, 10, 1623.

48 J. Wei, S. Wan, P. Zhang, H. Ding, X. Chen, H. M. Xiong, S. Gao and X. Wei, New J. Chem., 2018, 42, 6763.

49 M. Sevilla, G. A. Ferrero and A. B. Fuertes, Chem. Mater., 2017, 29, 6900.

50 J. Li, Q. Jiang, L. Wei, L. Zhong and X. Wang, J. Mater. Chem. A, 2020, 8, 1469.

51 J. Wang, Q. Yang, W. Yang, H. Pei, L. Zhang, T. Zhang, N. Hu, Y. Suo and J. Wang, J. Mater. Chem. A, 2018, 6, 16690.

52 Q. Jiang, Y. Wang, Y. Gao and Y. Zhang, Environ. Sci. Pollut. Res., 2019, 26, 30268.

53 H. Lin, C. Xu, Q. Wang, J. Wu, Y. Wang, Y. Zhang and G. Fan, Int. J. Hydrogen Energy, 2019, 44, 21527.

54 N. Balahmar and R. Mokaya, J. Mater. Chem. A, 2019, 7, 17466. 55 A. Altwala and R. Mokaya, Energy Environ. Sci., 2020, 13, 2967.

56 T. Ungár, J. Gubicza, G. Ribárik, C. Pantea and T. W. Zerda, Carbon, 2002, 40, 929.

57 L. Zhang, J. Zhang, H. Fu, H. Zhang, H. Liu, Y. Wan, S. Zheng and Z. Xu, Microporous Mesoporous Mater., 2018, 260, 59.

58 J. Rodriguez-Mirasol, T. Cordero, L. Radovic and J. Rodriguez, Chem. Mater., 1998, 10, 550.

59 F. Su, X. Zhao, L. Lv and Z. Zhou, Carbon, 2004, 42, 2821.

60 J. Wang and S. Kaskel, J. Mater. Chem., 2012, 22, 23710.

61 K. C. Bedin, A. C. Martins, A. L. Cazetta, O. Pezoti and V. C. Almeida, Chem. Eng. J., 2016, 286, 476.

62 A. R. Millward and O. M. Yaghi, J. Am. Chem. Soc., 2005, 127, 17998.

63 K. Sumida, D. L. Rogow, J. A. Mason, T. M. McDonald, E. D. Bloch, Z. R. Herm, T. Bae and J. R. Long, Chem. Rev., 2012, 112, 724 . 